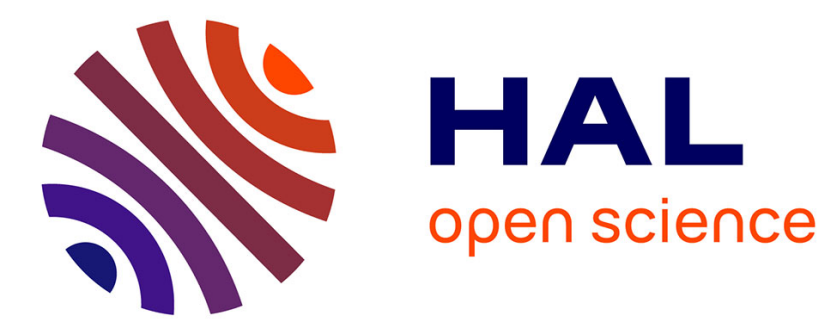

\title{
Recherches sur les origines de Grenoble d'après l'étude du mobilier archéologique: la fouille du parking Lafayette
}

Bernard Dangréaux

\section{To cite this version:}

Bernard Dangréaux. Recherches sur les origines de Grenoble d'après l'étude du mobilier archéologique : la fouille du parking Lafayette. Gallia - Fouilles et monuments archéologiques en France métropolitaine, 1989, 46, pp.71-102. 10.3406/galia.1989.2892 . hal-01939637

\section{HAL Id: hal-01939637 \\ https://hal.science/hal-01939637}

Submitted on 12 Feb 2020

HAL is a multi-disciplinary open access archive for the deposit and dissemination of scientific research documents, whether they are published or not. The documents may come from teaching and research institutions in France or abroad, or from public or private research centers.
L'archive ouverte pluridisciplinaire HAL, est destinée au dépôt et à la diffusion de documents scientifiques de niveau recherche, publiés ou non, émanant des établissements d'enseignement et de recherche français ou étrangers, des laboratoires publics ou privés.

\section{(ㅇ)(1) $\$$}

Distributed under a Creative Commons Attribution - NonCommercial - NoDerivatives $\mid 4.0$ 


\title{
RECHERCHES SUR LES ORIGINES DE GRENOBLE D'APRÈS L'ÉTUDE DU MOBILIER ARCHÉOLOGIQUE La fouille du parking Lafayette
}

\author{
par Bernard DANGREAUX
}

La fouille du parking Lafayette eut lieu en 1974. Elle contribua, avec celle effectuée en 1963 rue de la République, à tracer les grandes lignes de l'évolution d'un quartier du Grenoble antique. Aujourd'hui, l'étude de son moblier archéologique vient préciser la chronologie des différentes étapes de cette évolution et souligner l'existence d'u $u$ production céramique originale. L'ensemble des données enfin, permet de s'interroger sur la présence d'un résểu urbain quadrillé.

IIA rchaeological excavations on the site of the Lafayette carpark were made in 1974. These, together with those made in the "r at de la République» in 1963, have made an important contribution to our knowledge of the development of this district of A ie it Grenoble. The study of the archaeological findings has now clarified the chronology of the different stages of this deveto ment and confirmed the existence of an unprecedented local pottery industry. Taken as a whole, the findings may inaticate the presence of a rectangular urban street plan.

La fouille du parking Lafayette s'est déroulée à l'occasion de la construction de la Maison du Tourisme sous laquelle étaient prévus plusieurs niveaux de garages souterrains. Une fouille de sauvetage fut conduite, sous la direction de MM. A. Bocquet et M. Colardelle, du 11 mars au 25 avril 1974. Menée dans des conditions extrêmement difficiles (les travaux de terrassement du chantier ne furent jamais interrompus) la fouille ne put que permettre le dégagement des vestiges non encore détruits et nombre d'informations, quand elles ne furent pas perdues, ne purent être exploitées convenablement. Néanmoins les observations des archéologues, ajoutées à celles déjà exploitées lors de la fouille des remparts, rue de la République, en 1963 (Bocquet, 1968) permirent de suivre dans les grandes lignes (cf. infra) les avatars d'un quartier urbain par la suite relégué extra-muros. L'étude du matériel issu de la fouille du parking Lafayette vient aujourd'hui compléter et préciser les éléments connus alors.

\section{LES DONNEES OFFERTES PAR LE TERRAIN}

\section{LA STRATIGRAPHIE}

La stratigraphie relevée lors des fouilles de la rue de la République ${ }^{1}$ s'est trouvée confirmée à l'emplacement du parking Lafayette (fig. 1 a et b). Les coupes observées dans les deux fouilles offrent en effet une même séquence stratigraphique (fig. 2) :

- substrat de limon sableux (couche 8), supposé être le produit d'une sédimentation fluviatile, s'étendant sur l'ensemble du site de manière sensi-

1 La fouille de la rue de la République fit suite aux travaux de terrassement qui mirent au jour quelque $65 \mathrm{~m}$ de l'enceinte du $\|^{\prime} \mathrm{s}$. En réalité, parler de fouilles est ici impropre dans la mesure où l'intervention des archéologues (A. Bocquet et les membres du Centre de Documentation de la Préhistoire Alpine) fut postérieure à la réalisation de l'excavation et de ce fait souvent limitée à l'examen des coupes de terrain. 


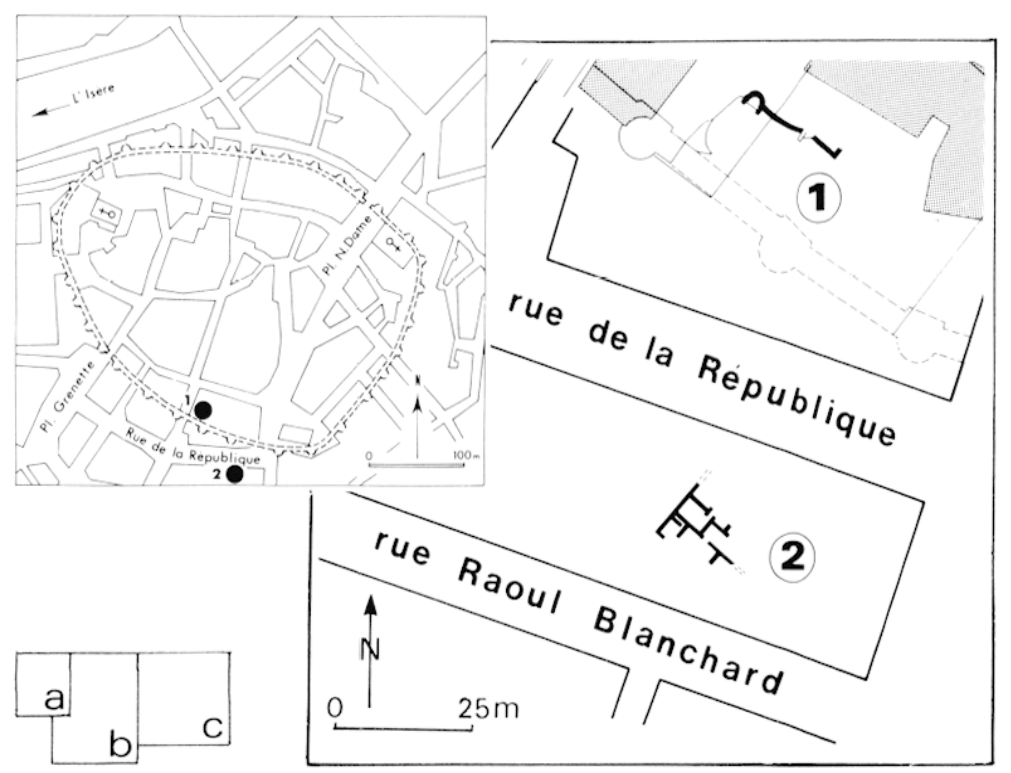

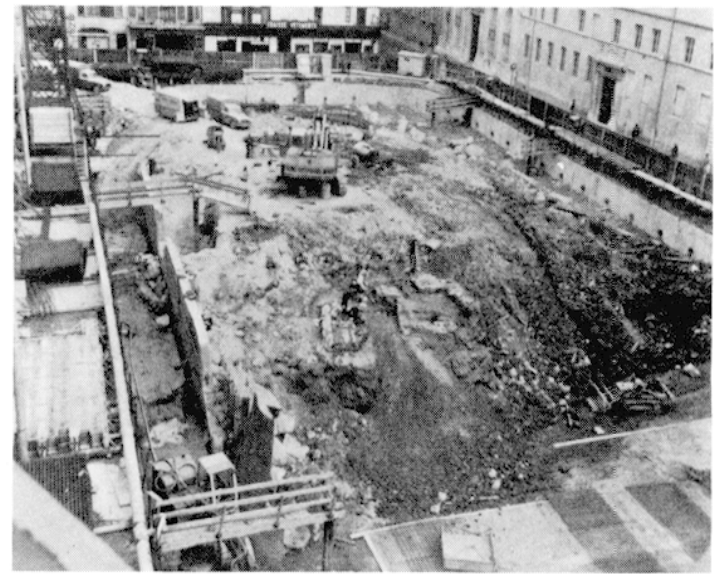

Fig. 1 - a et b, situation des fouilles effectuées dans le quartier République;

1 , rue de la République; 2, parking Lafayette. c, vue générale du chantier du parking Lafayette. blement horizontale à la cote $-5 \mathrm{~m}$ par rapport au sol actuel. Ce dépôt s'est révélé totalement stérile.

- couche mince et discontinue (couche 7) de matériaux divers, très érodés. Cette couche, également variable en épaisseur $(2 \dot{a} 10 \mathrm{~cm})$ a offert quelques tessons de céramique au milieu de nombreux petits fragments de briques, tegulae et imbrices.

- banc de gravier sableux (couche 6), stérile malgré son épaisseur (10 à $40 \mathrm{~cm}$ ).

- accumulation sur 5 à $20 \mathrm{~cm}$ d'épaisseur de différents malériaux : fragments de tegulae et de briques, tessons de céramiques, restes osseux, charbon de bois etc. (couche 5 ).

- remblai très hétérogène (couches 4 et 2 ou couche 2/4 lorsque la séparation n'a pu être précisée) contenant des galets, des matériaux de démolition ainsi que du matériel d'époque gallo-romaine, et donnant "l'impression d'un remplissage et d'un nivellement ${ }^{2}$. D'une manière générale, le niveau supérieur de ce remblai offre une moindre abondance de fragments de tegulae.

- couche de remplissage moderne (couche 1) dans laquelle ne figure aucun reste de matériaux antiques.

Au-delà de ces données générales, on notera une couche de mortier de tuileau (couche 3.1), très vraisemblablement sol de travail à mettre en relation

2 Toutes les références aux observations effectuées sur le terrain sont tirées des rapports de fouilles relatifs aux deux interventions (cf. bibliographie: Bocquet, 1963 et Bocquet, Colardelle, 1974). Je remercie leurs auteurs pour m'avoir autorisé à en faire ètat. avec l'edification des remparts, et différents niveaux d'habilat. Une première construction apparait, rue de la République, dans la partie est. Son appareil est décrit "assez régulier" avec des joints soulignés au fer, et ses fondations, reconnues sur une hauteur de $30 \mathrm{~cm}$, entaillent le substrat (couche 8 ). C'est à ce même niveau que l'on trouve l'habitat mis au jour à l'emplacement du parking Lafayette. Une seconde' structure maconnée est également visible dans la partic ouest de la rue de la République; elle se distingue nettement de la première par un appareil en moellons assez irréguliers, mal équarris et noyés de mortier gris. Les murs reposent sans la perforer sur la couche ら et entre ceux-ci, deux sols prouvent à l'évidence un remaniement de l'aire habitée.

Ces observations permettent de proposer une chronologie relative : la couche 6 , dont le caractère fluviatile marquerait la trace d'une inondation ${ }^{3}$, est plaquée contre le mur de la première construction; elle lui est donc postérieure. La structure aux moellons irréguliers est fondée, au contraire, audessus de cette couche; les deux bâtiments ne sont donc pas de construction contemporaine.

A cette datation relative s'ajoutaient des arguments tendant à cerner une chronologie absolue. Aucun vestige de l'indépendance gauloise ou d'âges plus anciens n'avait été retrouvé entre 5 et $10 \mathrm{~m}$ de profondeur; la première installation, matérialisée

3 A. Bocquet a pensé que les graviers de la couche 6 "d une puissance non négligeable" pouvaient ètre les temoins d'une inondation. Il ajoute dans son rapport que $\mathbf{M}$. J. SarrotReynauld, Professeur à l'Institut de Ciéologie de la facultè des Sciences de Grenoble, après une visite sur le terrain "pense pouvoir affirmer lui aussi l'origine fluviatile de cette couchen. 


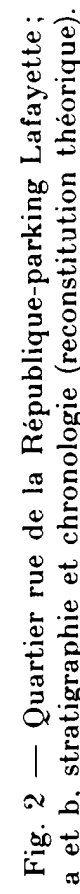
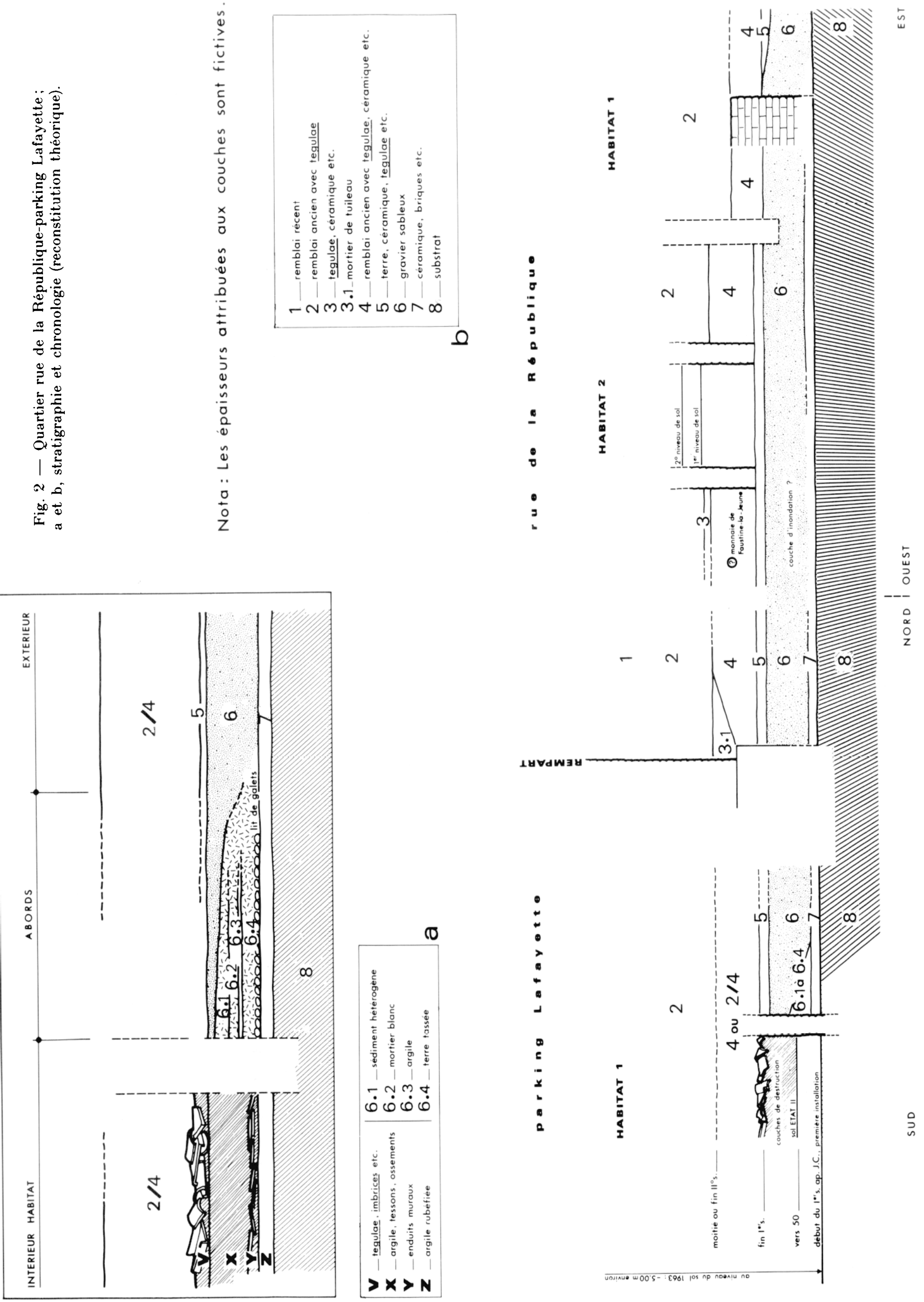
par la construction aux joints lissés, fut datée sur ce dernier critère du $\mathbf{I}^{\text {er }} \mathrm{s}$. de notre ère ${ }^{4}$. A l'autre extrémité du faciès stratigraphique, la couche 3.1 , située à la base du rempart fixait quant à elle un terminus ante quem à la fin du $\mathrm{II}^{*} \mathrm{~s}^{5}$ pour la couche 4 qui lui est immédiatement inférieure; cela s'accorderait d'ailleurs avec la découverte ${ }^{6}$ d'une pièce de monnaie à l'effigie de Faustine la Jeune dans cette même couche 4 .

L'ensemble de ces éléments posait donc pour la fouille de la rue de la République quelques jalons chronologiques à l'intérieur desquels s'inscrit l'habitat mis au jour au parking Lafayette.

\section{L'HABITAT}

Il est certain que la zone d'habitat s'étendait sur une superficie plus vaste que celle mise en évidence par la fouille. Les travaux de fondation, déjà très engagés côté nord lorsque fut autorisée l'intervention des archéologues, et les caves des constructions $\mathrm{du} \mathrm{XIX}^{\mathrm{e}} \mathrm{s}$, côtés est et sud, ont tous deux détruit une partie de l'ensemble (fig. 1 c et 5, 1). Néanmoins plusieurs conclusions purent être tirées de la fouille des structures dégagées.

\section{LA STRATIGRAPHIE}

La stratigraphie se modifie de façon fort sensible, au regard des lignes générales, à la limite du bâtiment (fig. $2 \mathrm{a}$ ). On trouve ainsi, à la surface de la couche 7 , un lit bien marqué de galets puis, audessus de ce lit, une succession de petites couches bien individualisées : terre tassée (couche 6.4), fin dépôt d'argile (couche 6.3), lit de mortier blanc (couche 6.2) et enfin (couche 6.1) une épaisseur variable d'éclats de tuile dans un sédiment hétérogè-

4 C'est sur la présence de joints lissés que s'appuyait A. Bocquet pour proposer une première implantation dans le courant du jer $\mathrm{s}$. de notre ère. Il se référait en cela à la mention d'A. Grenier attribuant à l'époque julio-claudienne les joints marqués au fer. On sait maintenant que cette caractéristique n'est pas le fait du seul jer $\mathbf{s}$. Ainsi à Saint-Romain-en-Gal, dans la "Maison des Dieux Océans", cette technique se rencontre aussi bien dans les ètats II et III ( $\mathrm{I}^{\mathrm{er}} \mathrm{s}$. après J.-C.) qu'à l'état $\mathrm{IVb}$, daté du début du $\mathrm{II}^{\mathrm{e}} \mathrm{s}$. (information A. Desbat). La datation fondée sur ce fait n'est cependant pas démentie par les autres découvertes archéologiques.

5 Les dédicaces accordées par les empereurs Dioclètien et Maximien aux deux portes de la ville (CIL, XII, 2229) permettent de proposer une datation comprise entre 286 , année à partir de laquelle les deux empereurs règnent conjointement, et 293 lorsque est mise en place la Tétrarchie.

6 En fait le rapport de fouille mentionne ceci : "une pièce de monnaie a été récupérée en notre absence très probablement dans la couche 4 , près de la tour». ne. Quant à la couche 6 (banc sableux stérile) elle vient buter, en s'amincissant, sur le mur; on retrouve là un fait mentionné rue de la République (cf. supra).

L'intérieur de l'habitat offre lui aussi plusieurs niveaux entre la couche de remplissage $2 / 4$ et le substrat 8. Trois d'entre eux peuvent être mis en relation avec la destruction de l'édifice : une couche de tegulae et d'imbrices tout d'abord (couche V); puis une couche d'argile (effondrement des murs?) sur environ $30 \mathrm{~cm}$ (couche $X$ ); enfin un niveau de lits d'enduits muraux (couche Y). Sous ce dernier, et avant de retrouver le substrat, on rencontre une couche d'argile rubéfiée (couche Z) contenant des tessons.

\section{LE PLAN (fig. 3 et 4)}

En dépit d'un plan tronqué (seule la limite nordouest est connuc), on peut distinguer plusieurs aménagements successifs :

\section{L'état I}

A l'état initial (fig. 4, 1), le bâtiment se limite à un rectangle dans lequel les pièces $2,1,4$ et 5 forment un ensemble organisé. Les murs reposent sur des fondations dont on a pu préciser les niveaux inférieur $(\mathrm{z}=-3,06 \mathrm{~m})$ et supérieur $(\mathrm{z}=-2,80 \mathrm{~m})^{7}$; ils délimitent des pièces au sol en terre battue que l'on ne retrouve pas dans les espaces 6 et 7. Dès lors il est possible d'envisager un habitat disposé autour d'une cour dont l'accès serait matérialisé par les massifs A5 et $\mathrm{A} 9$.

\section{L'état II}

Une deuxième phase de construction (fig. 4,2 ) vient modifier ce plan. Son emprise au sol est augmentée comme en témoigne la façade nord-ouest, prolongée d'un mur maçonné prenant appui sur l'angle A3. Parallèlement, sa distribution interne est repensée; des murs de terre créent de nouvelles divisions (pièces 3,6 et 7 du plan); les accès sont remaniés : le seuil de la pièce 4 est plus étroit de $1 \mathrm{~m}$ maintenant et l'érection d'un mur depuis le massif A6 dessine au sol un passage. Enfin l'aménagement de certaines pièces est repris. Le sol des pièces 1 et 4 , toujours en terre battue, est exhaussé $(\mathrm{z}=-2,54 \mathrm{~m})$, le niveau de l'espace antérieur à la création des pièces 6 et 7 étant quant à lui relevé par un remblai (de galets?). En élévation, des peintures murales décorent les pièces 1, 4 et 6 . C'est à cette phase d'agrandissement

7 Les cotes sont ici seulement relatives, le niveau de référence n'ayant pu être retrouvé. 
et de réfection que semblent devoir correspondre les couches 6.1 à 6.4 observées à la limite du bâtiment (fig. 2). Ce deuxième ètat marque en tout cas l'ultime extension de l'habitat.

\section{L'étal III}

Le troisième état (fig. 4,3) ne consiste en effet qu'en un changement de la fonction attribuée à la pièce 2 : une construction semi-circulaire en pierres sèches $y$ est érigée et l'on dépose, contre le massif A5, une quarantaine de pesons pyramidaux.

Les raisons de cette transformation s'expliquent difficilement. De toute évidence, le bâtiment est encore debout : la structure de pierres sèches s'appuie contre le soubassement A3, les pesons sont visiblement contenus par le mur Al0 (fig. 5, 3) et la couche de tuiles illustrant la phase de destruction recouvre ces éléments (fig. $3 \mathrm{~b}$ ). On notera donc

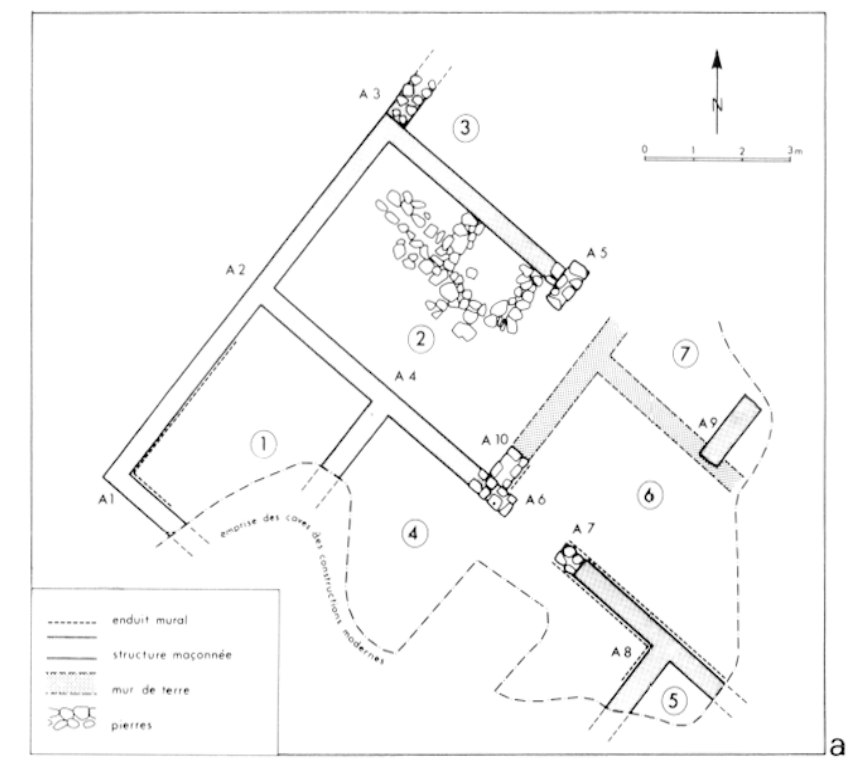

seulement que cet aménagement représente le dernier avatar de l'édifice. Viendront ensuite la destruction puis le comblement.

\section{LES TECHNIQUES DE CONSTRUCTION}

On retiendra avant tout que les structures maçonnées se présentent de manière sensiblement identique quel que soit l'état I ou II auquel elles appartiennent. Il est seulement rapporté que la construction secondaire se distingue de la phase initiale par l'absence de liaison aux angles avec les murs de l'édifice primitif et par le mode d'exécution beaucoup moins soigné : irrégularité de l'appareil, moindre qualité des mortiers. Pour le reste l'exécution s'appuie sur un même principe : murs appareillés reposant sur un soubassement de moellons liés au mortier et un radier composé de deux rangs de galets (fig. 5, 2). On ne sait si ces structures sont les vestiges d'une élévation entièrement maçonnée ou s'il s'agit là d'un soubassement destiné à recevoir une construction de terre. Rien pourtant ne contredit cette éventualité : l'arase des murs, à peu près régulière, et la stratigraphie observée dans la pièce $1^{8}$ pourraient même accréditer un tel type de construction.

8 A la fouille, on a distingué nettement deux lits horizontaux (d'enduits?) séparés par une couche. On peut voir dans celle-ci les vestiges d'un mur effondré sur le sol d'occupation.

La présence d'une architecture de terre n'est également pas à exclure pour les constructions de la rue de la République : on y retrouve la mème assise régulière à quelque $60 \mathrm{~cm}$ au-dessus du sol et la même absence de matériaux durs dans les couches de remplissage.
Fig. 3 - a, plan de l'habitat; b, vue axonométrique de l'habitat.

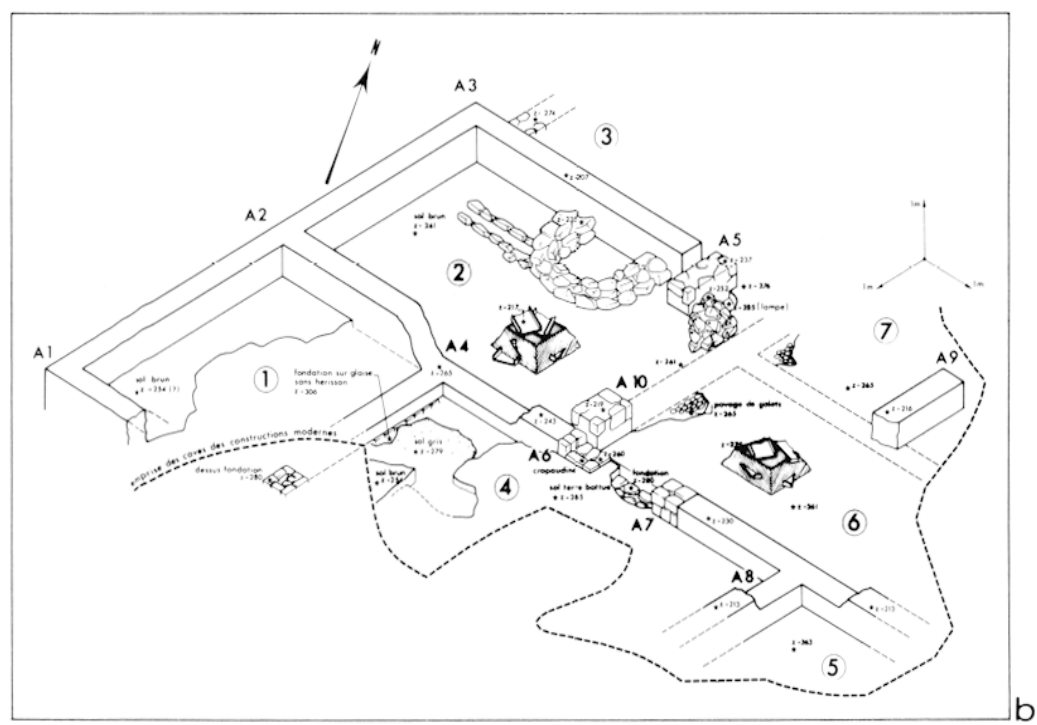




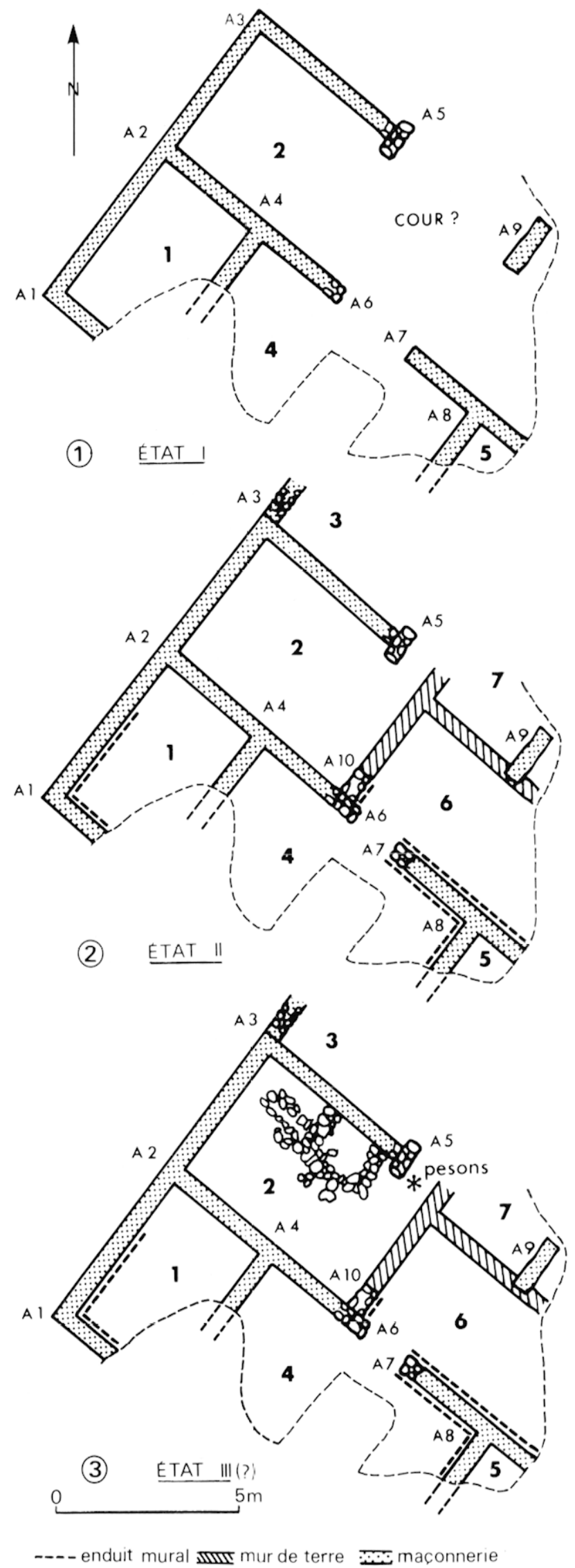

Fig. 4 - Les différentes phases d'occupation de l'habitat.
Il est en revanche certain que des murs de terre ont été élevés à l'intérieur de l'habitat lors de la restructuration de l'espace (état II). On sait en effet (Desbat, 1981 et 1983) que, dans l'élévation d'un mur à colombages, la pose d'une sablière en bois précède l'aménagement des sols. A la fouille, son négatif apparaît ainsi en tranchée. C'est bien ce que l'on rencontre entre les pièces 2,6 et 7 ; on peut donc être assuré du recours à ce mode de construction. Dès lors, on peut voir aussi dans le massif A10 le support d'un montant venant armer le mur. Il ne faudrait donc plus parler de pisé comme cela fut avancé.

\section{LE DÉCOR INTÉRIEUR}

Le décor intérieur est attesté par de nombreux vestiges d'enduits peints dans les pièces 1,4 et 6 (fig. $3 \mathrm{a}$ ), à la base des murs ${ }^{9}$ ou dans les couches de destruction.

Le relief des mortiers (fig. 6,3 à 5 ) montre les stries d'ancrage que l'on pratiquait sur les murs de terre. Il confirme donc encore l'existence de ce mode de construction. Pour les enduits peints, on peut distinguer cinq groupes ${ }^{10}$ selon l'aspect de leur couverture picturale :

- groupe A : champ blanc décoré de formes ovoïdes rouge ocre dessinées sur champ marron;

- groupe B : champ blanc moucheté à l'imitation du marbre;

- groupe C : champ ocre jaune, à filet d'encadrement intérieur vert, présentant un décor végétal composé de feuilles noires de formes ovoïdes ou en palmettes. Deux fragments isolés laissent également apercevoir des rinceaux marrons terminés par un renflement ovale;

- groupe D : champ ocre rouge, à filet d'encadrement intérieur noir, limité par une bordure (ou bande de séparation) de couleur verte doublée d'une bordure vert clair ou blanche très passée (fig. 6,1 );

- groupe E : champ noir à triple filet d'encadrement intérieur (un filet central marron et deux filets latéraux jaunes) à angle droit. Une bordure verte limite le champ noir (fig. 6, 2).

9 On remarquera que les enduits peints recouvrent. les maçonneries qui ont conduit à un rétrécissement du seuil séparant les pièces 4 et 6 . Ce décor ne peut donc appartenir à la première occupation de l'habitat.

10 La description des peintures murales suit la terminologie préconisée par le Centre d'études des peintures murales romaines (C.NRS) dans son bulletin de liaison n" 7 (Barbet, 1984). 

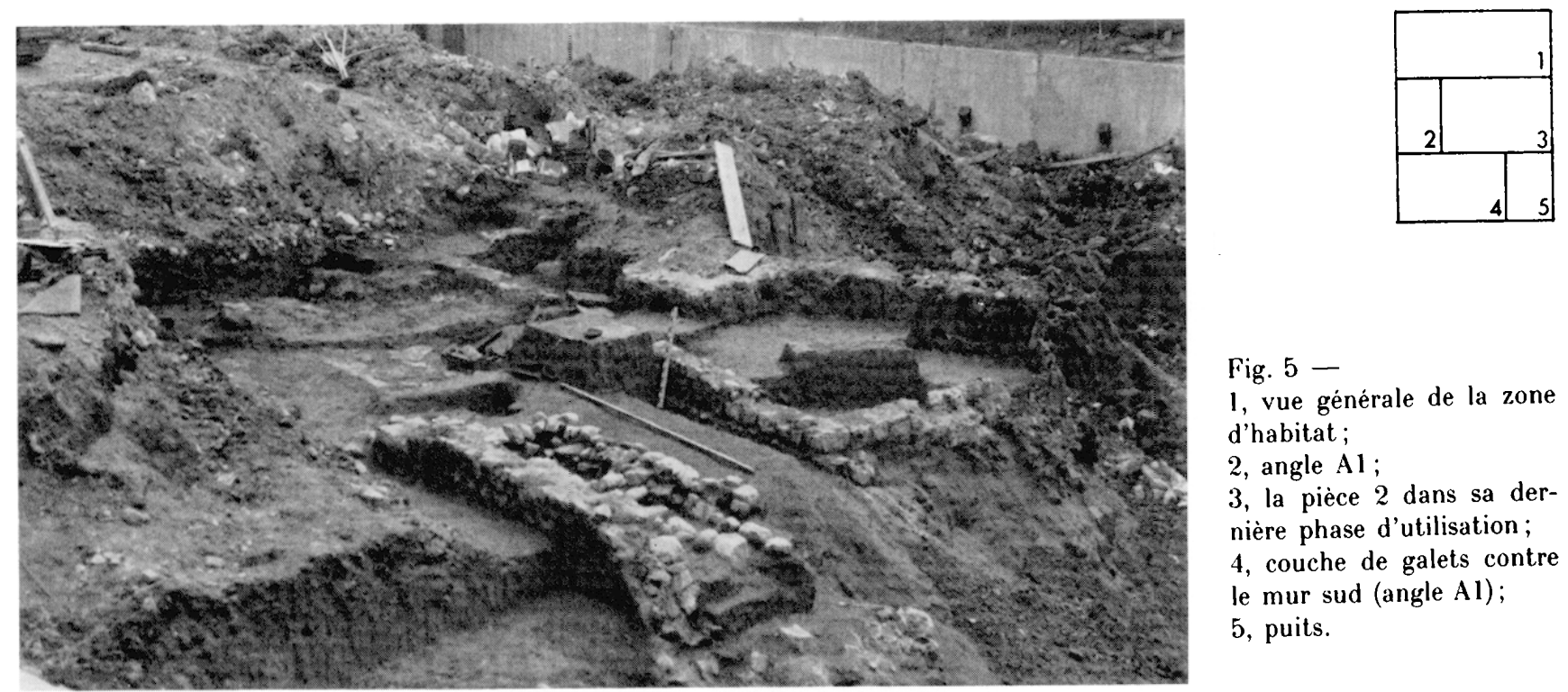

Fig. 5

1, vue générale de la zone d'habitat;

2 , angle $\mathrm{Al}$;

3 , la pièce 2 dans sa dernière phase d'utilisation;

4 , couche de galets contre le mur sud (angle Al);

5 , puits.
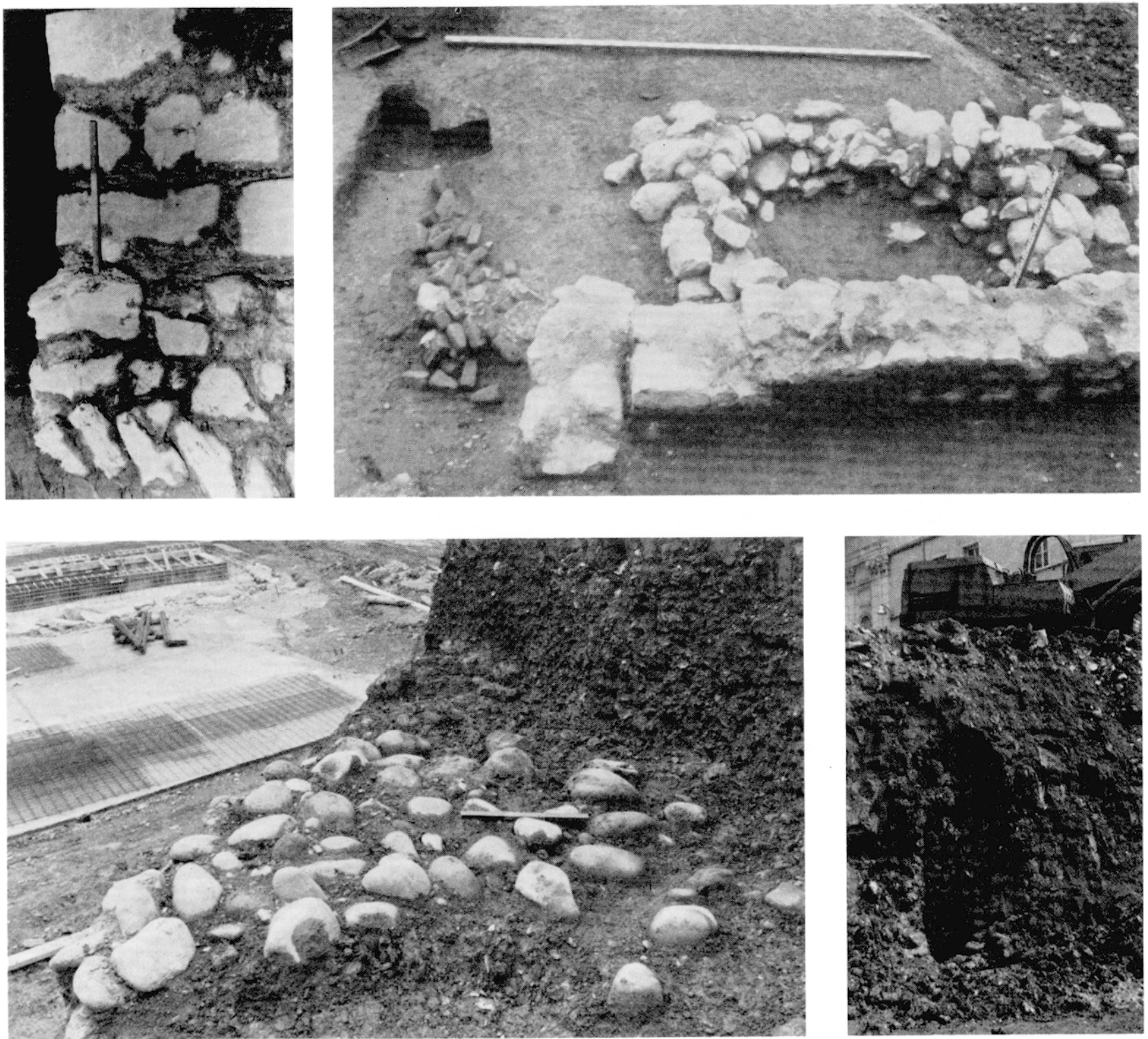

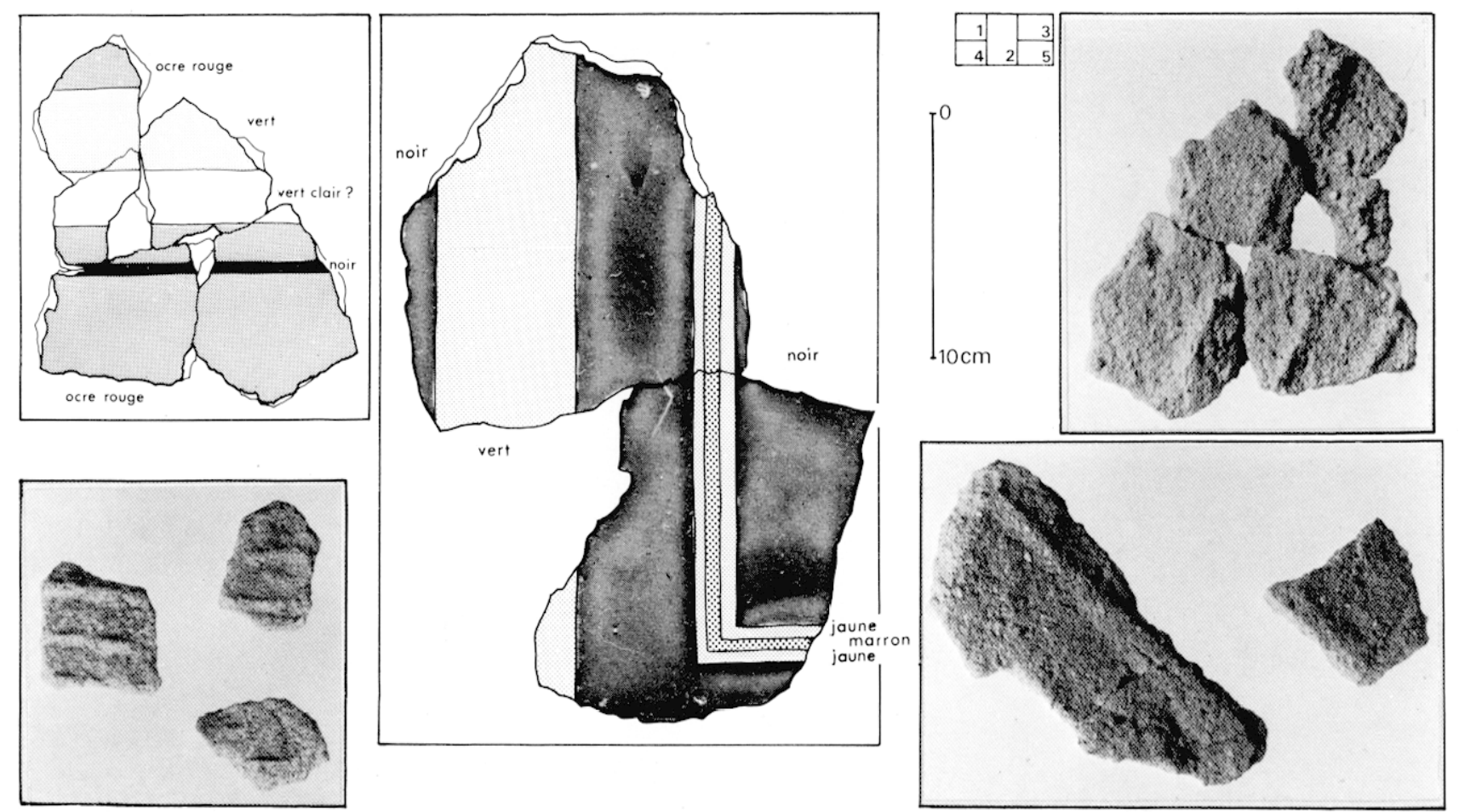

Fig. 6 - Enduits peints : 1, groupe D; 2, groupe E. Revers de mortier : 3, groupe D; 4, groupe B; 5, groupe C.

Certains de ces décors offrent des indices d'ordre chronologique. C'est le cas notamment du panneau ocre rouge du groupe $D$ et surtout le triple filet du groupe E. On peut en effet voir en eux des témoins du III $^{e}$ style pompéien pour lequel on propose (Barbet, 1982-1983) un terminus ante quem proche de la fin de la première moitié du $\mathrm{I}^{\mathrm{er}} \mathrm{s}$. de notre ère.

\section{Autres vestiges}

Différents vestiges ont également été mis au jour dans l'environnement de l'habitat : une couche de galets, observée dans les coupes et contre le mur sud du bâtiment, deux amphores trouvées ensemble fichées en terre, et un puits ${ }^{11}$.

\section{LA COUCHE DE GALETS}

Aperçue dans les coupes, la couche de galets extérieure à l'habitat n'a été mise en évidence que sur une faible superficie contre le mur sud de l'angle A1 (fig. 5, 4). Très amplement entamée au sud par les fondations d'époque moderne, elle a

11 Un second puits fut découvert; moins profond et de construction différente du premier, il n'a révélé que du matériel céramique postérieur au Xve $\mathrm{s}$. Il n'a donc pas été pris en compte dans cette étude. également disparu dans les terrassements de la zone nord du chantier.

La position de cette couche de galets à la surface de la couche 7, considérée rue de la République comme le premier témoin d'une occupation humaine, invite à voir dans cette installation formant un sol pavé, un aménagement contemporain de la première construction.

\section{LES AMPHORES}

Deux amphores furent découvertes lors de travaux exécutés à la pelle mécanique. L'une est une amphore à saumures de type Beltrán Ila (fig. 15, 13); l'autre fut cassée par l'engin et ses tessons dispersés. Aucune ne put être repérée en plan ou en stratigraphie. Les raisons qui ont conduit à leur implantation conjointe et verticale, de façon manifestement délibérée, restent inconnues.

\section{LE PUITS}

Seule la partie inférieure de ce puits était conservée, la partie haute semblant avoir été arasée (fig. 5, 5).

Découvert dans le front de taille dù à l'avancement des travaux, ce puits n'a pu être observé que sur la moitié de sa circonférence. Il a cependant été possible de noter que les parois étaient formées de moellons et de galets non maçonnés et que l'ensem- 
ble avait d'abord été cuvelé et étayé par des planches disposées sans ordre apparent.

Le remplissage de ce puits a révélé un important mobilier archéologique que les conditions imposées à l'intervention de sauvetage n'ont pas permis de situer en stratigraphie. Pour les mêmes raisons, cette construction n'a pu être rattachée aux vestiges de l'habitat ni en plan ni en niveau.

\section{CONTEXTE ARCHÉLOGIQUE ET MOBILIER}

Les observations enregistrées lors de la fouille (cf. tableau) ont autorisé la localisation en plan et/ou en altimétrie de certains faits archéologiques. On s'aperçoit (fig. 7) que plusieurs d'entre eux peuvent être regroupés soit dans une même zone (E1, E2, E3 par exemple), soit dans une même couche (B11, B15 notamment) soit encore dans un mème ensemble de couches successives (ainsi B8, B7). C'est donc en tenant compte de ces rapprochements éventuels que le mobilier est ici intégré dans son contexte archéologique $^{12}$.

\section{L'INTÉRIEUR DU BÂTIMENT}

\section{PIÉCE $1, B 20$}

Seul un fond de bol en céramique peinte (fig. 16, 4) a été enregistré dans ce contexte. On peut y reconnaître un pied de bol à renflement interne semblable à ceux découverts à Genève dans un contexte daté du ${ }^{\text {er }} \mathrm{s}$. ou des premières années du II ${ }^{\text {e }}$. (Paunier, 1981, p. 55-70 et forme 24 p. 175). Un bord de ce type de bol a d'ailleurs été recueilli hors stratigraphie, au parking Lafayette (fig. 16, 3).

12 N'est exploité ici que le matériel apportant des indices chronologiques. En revanche, on trouvera en annexe l'ensemble du mobilier composant chaque fait archéologique, à l'exception du matériel relevé hors stratigraphie.

\begin{tabular}{|c|c|c|c|}
\hline & Désignation & \multicolumn{2}{|c|}{ Observations enregistrées lors de la fouille } \\
\hline & & description & altimétrie relative \\
\hline \multirow{20}{*}{ 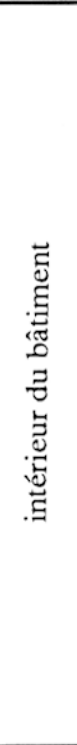 } & B1 & couche tuiles, angle 2 & $\mathrm{z}=-217$ \\
\hline & B2 & sol brun, angle 2 & $z=-261$ \\
\hline & B3 & sol brun supérieur & \\
\hline & B4 & sol brun supérieur, angle 2 & \\
\hline & B5 & couche tuiles inférieures (au-dessus du sol brun) & \\
\hline & B6 & couche sous le sol brun supérieur & \\
\hline & B7 & couche des quarante pesons & $\mathrm{z}=-252$ (sommet) \\
\hline & B8 & couche lampe romaine & $z=-285$ \\
\hline & B9 & jatte à côté de l'angle du mur & \\
\hline & $\mathrm{B} 10$ & pièce 1 & \\
\hline & B11 & remplissage couche 4 & \\
\hline & $\mathrm{B} 12$ & poche grise & $z=-255$ \\
\hline & $\mathrm{B} 13$ & couche sur argile vierge, angle 2 & \\
\hline & B14 & tranchée & \\
\hline & $\mathrm{B} 15$ & couche 4 & \\
\hline & B16 & sol supérieur, angle 2 & \\
\hline & B17 & au niveau des murs & \\
\hline & B18 & angle 2 & \\
\hline & B19 & angle 2 & $\mathrm{z}=-280$ \\
\hline & $\mathrm{B} 20$ & angle 1 & $z=-280$ \\
\hline \multirow{6}{*}{ 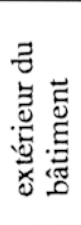 } & E1 & extérieur, angle 2 & \\
\hline & E2 & extérieur, angle 2 & $z=-260$ \\
\hline & E3 & extérieur, angle 2 & $z=-276$ \\
\hline & $\mathrm{E} 4$ & extérieur, couche 7 & \\
\hline & E5 & extérieur, angle 3 & $z=-280$ \\
\hline & E6 & fosse à céramique, à l'ouest des murs extérieurs & \\
\hline \multirow{6}{*}{ 峁 } & D1 & fosse 1, coupe 2 & \\
\hline & D2 & fosse 2 , coupe 3 & \\
\hline & D3 & dépotoir à proximité de l'amphore 2 & \\
\hline & D4 & fosse, couche 7 & \\
\hline & Puits & puits gallo-romain & \\
\hline & H.S. & hors stratigraphie & \\
\hline
\end{tabular}




\section{PIÉCE 1, B10}

Aucun des tessons présents ne peut être attribué à une forme particulière. On notera que la céramique commune sombre n'est représentée que par des fragments de céramique non tournée mais l'absence de référence locale empêche toute affirmation d'ordre chronologique.

PIÉCE 2, B7, B8

Le seul élément daté de cet ensemble réside dans la lampe à volutes (fig. 17, 1) issue de B8. Il reste en effet difficile d'attribuer une datation aux quarante poids de suspension ou "pesons de tisserand" découverts en $\mathrm{B} 7$ : on les rencontre de façon quasi systématique sur chaque site gallo-romain et les divers graffites ou marques que l'on peut distinguer sur ce matériel (fig. 17, 3 à 12) n'apportent aucune précision; le A sans barre horizontale, par exemple, figure dans la plupart des documents écrits (Mallon et alii, 1939) et il n'existe aucun rapport entre graffites ou marques et poids : les trois pesons marqués $E R$ (fig. 17, 4, 5 et 6 ) pèsent respectivement 550,580 et $620 \mathrm{~g}$; à l'inverse, deux exemplaires ont un poids très voisin alors qu'ils présentent l'un deux estampilles, l'autre trois (fig. 17, 9 et 10). C'est donc la lampe à volutes, généralement datée du $\mathrm{I}^{\mathrm{er}} \mathrm{s}$. après J.-C. (Ponsich, s.d.), qui donne le terminus post quem de B8.

\section{PIĖCE 2, B19, B6, B2-3-4-16, B5, B1}

Un sol d'occupation a été reconnu à la fouille à la cote $-2,61 \mathrm{~m}$ (fig. $3 \mathrm{~b}$ ). Tous les faits archéologiques situés au-dessus de ce niveau sont en fait contemporains : il s'agit d'une seule et même couche de destruction dans laquelle on retrouve de nombreux fragments de legulae et imbrices.

Le matériel céramique permettant de dater cette couche est important :

- sigillée : deux Drag. 27 (fig. 8, 4), un fragment de bord de Ritt. 9 (ou Drag. 4/22), deux Drag. 15/17 (fig. 8, 7), deux Drag. 18/31 (fig. 8, 5 et 6 ), et un fragment de lèvre de Ritt. 14 pour la sigillée lisse; un Drag. 30 (fig. 9, 2) pour la sigillée décorée;

- commune sombre : un pot ovoïde à épaule carénée (fig. 10, 1);

- commune claire : un mortier à lèvre en bandeau (fig. 14, 7);

- peinte : un bol dit "de Roanne" (fig. 16, 2);

- parois fines: un bol hémisphérique sablé

(fig. 16, 5).

Ce matériel est, dans son intégralité, représentatif des productions du $\mathrm{i}^{\mathrm{er}} \mathrm{s}$. Les formes sigillées (Vernhet, 1975), le pot ovoïde (Paunier, 1981, p. 264, $\mathrm{n}^{\circ}$ 639), le mortier à lèvre en bandeau (Desbat et alii, 1979), le bol dit "de Roanne» (Périchon, 1974) et le bol sablé (Paunier, 1981, p. 220), ainsi que l'absence de matériel produit au II $^{e}$ s., invitent à voir en la fin $\mathrm{du} \mathrm{I}^{\mathrm{er}} \mathrm{s}$. le terminus ante quem de cette couche de destruction. Le terminus post quem est à dater de 4050 , période à laquelle commence à être produit le Ritt. 14.

Les faits $\mathrm{B} 6$ et $\mathrm{B} 19$, situés sous le niveau d'occupation, ne bénéficient pas du moindre indice autorisant une datation.

\section{PIÉCE 2, B13, B18}

Aucune indication altimétrique ne vient préciser le niveau de ces deux faits. Il demeure donc impossible de les situer par rapport aux autres niveaux enregistrés dans l'angle 2 de cette pièce. De plus, la pauvreté du matériel qu'ils renferment l'un et l'autre interdit à la fois leur interprétation et leur datation.

\section{PIÉCES 6 el 7, B14}

L'interprétation de cette tranchée a déjà été évoquée plus haut : il s'agit vraisemblablement du négatif de la sablière d'un mur à colombages. Les vestiges découverts appartiennent donc à une phase antérieure à la construction de ces murs. Parmi ces vestiges, trop ténus pour être rapportés à une forme susceptible d'être datée, on remarquera un tesson de céramique sigillée italique ${ }^{13}$ et neuf de céramique commune sombre non tournée.

\section{Toutes PIĖCEs, B11-B15 (couche 4)}

La couche 4 est située dans les niveaux supérieurs de la fouille (fig. 2). Or on y retrouve un fragment de Goudineau 17 (fig. 8, 1) témoin du matériel le plus ancien en date sur le site (fin $\mathrm{I}^{\mathrm{er}} \mathrm{s}$. avant J.-C.; Goudineau, 1968)14. On peut donc confirmer l'impression de remplissage décrite lors de l'intervention sur le terrain et voir dans cette couche 4 un remblai succédant à la phase de destruction de l'habitat.

13 La détermination de l'origine de la production est fondée sur l'examen visuel de la pâte. On a proposé une production des ateliers de la Gaule du Sud pour une pâte rose présentant des petits points blancs ou une pâte rouge orange piquetée de points jaunes, et une production des ateliers du Centre de la Gaule pour une pâte jaune micacée ; la production italique se distingue d'elles par une pâte plus blanche.

14 Un bord, de forme Goudineau 18, (fig. 8, 2) a également été recueilli sur le site, mais hors stratigraphie. 


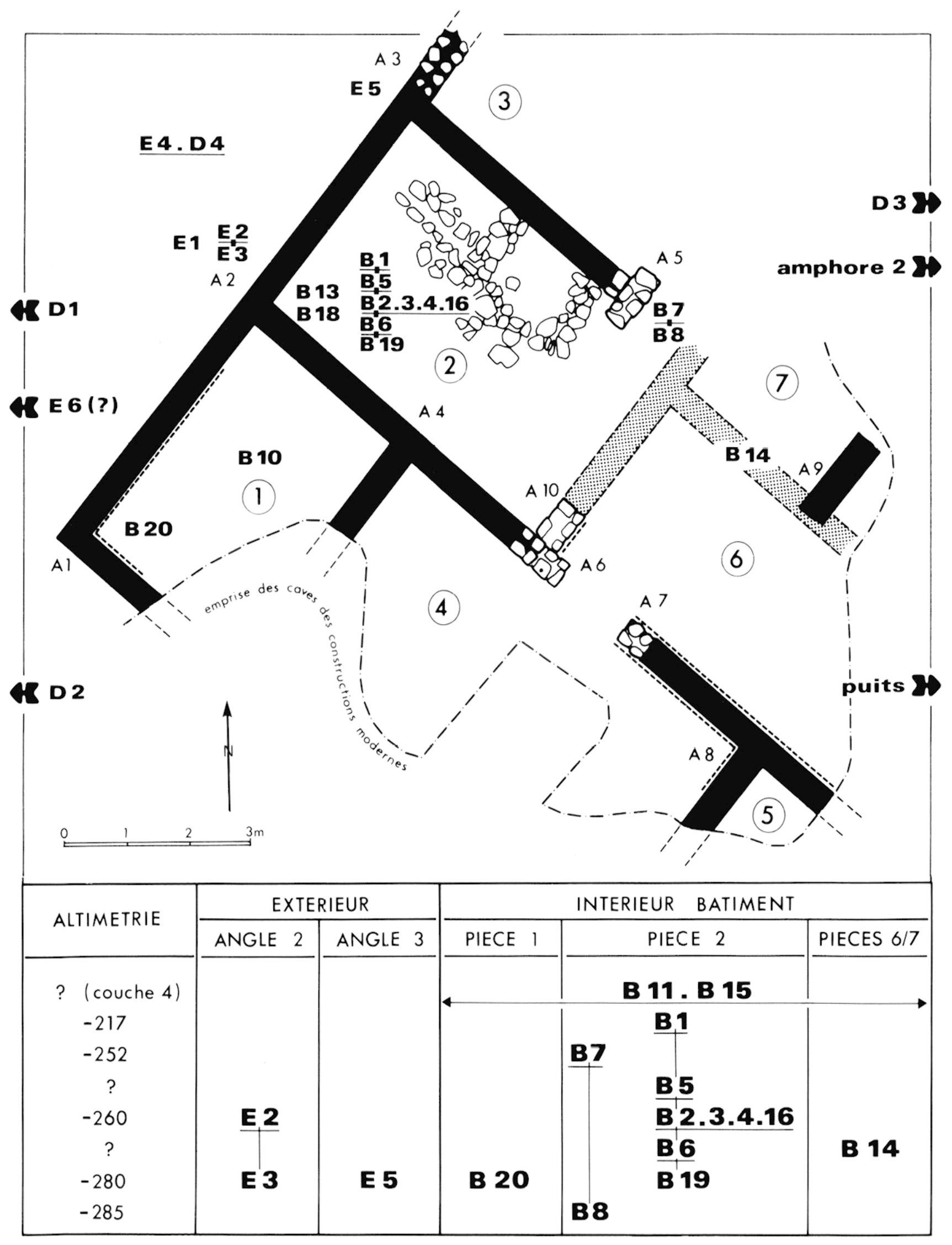

Fig. 7 - Situation des faits archéologiques. 


\section{FAITS ISOLÉs, B9, B12 et B17}

Les informations associées à ces trois faits n'ont pas permis leur localisation à l'intérieur du bâtiment. On notera toutefois que la cote $-2,55 \mathrm{~m}$ de B12 situe celui-ci au-dessus du sol d'occupation $(\mathrm{z}=-2,61 \mathrm{~m})$ et sous la couche supérieure de tuiles $(\mathrm{z}=-2,17 \mathrm{~m})$, à l'intérieur donc de la couche de destruction de l'habitat. La présence d'un calice en verre, ou carchesium, de type Isings 36a/MorinJean 98 (fig. 17, 2), typique selon Isings (1957) du $\mathrm{I}^{\mathrm{er}} \mathrm{s}{ }^{15}$, souligne encore l'absence de matériel produit postérieurement à la fin de ce même siècle.

\section{L'EXTÉRIEUR DE L'HABITAT}

\section{ANGLE 2, E1, E2-E3}

Ces trois faits ne sont différenciés que par leur situation altimétrique au demeurant inconnue pour le premier d'entre eux.

Le matériel sigillé, bien que fragmentaire (un bord de Drag. 15/17, un bord de Drag. 18/31, deux bords de Drag. 35 avec décor de "feuilles d'eau»), permet de proposer pour E1 un terminus post quem vers 60 après J.-C., date d'apparition de la forme Drag. 35 (Vernhet, 1975).

\section{ANGLE 3, E5}

Ce fait est situé en altimétrie au niveau des premiers vestiges de l'occupation mais son matériel n'apporte aucun élément précis de datation.

\section{FAGADE NORD-OUEST, E4-D4 (couche 7)}

Déjà reconnue lors de la fouille de la rue de la République, la couche 7 renvoie à la stratigraphie générale du quartier (fig. 2). Elle porte la trace de la première occupation humaine.

Le matériel recueilli, un fragment d'anse d'amphore Dressel 20, un bord de bol de Roanne (fig. 16, 1), est connu dès le début de l'ère chrétienne (Colls et alii, 1977; Périchon, 1974). Le lerminus post quem proposé pour le début de l'installation, début $\mathrm{i}^{\mathrm{r}} \mathrm{s}$. après J.-C. (cf. supra), se trouve ici confirmé.

15 Isings corrige la datation de Morin-Jean (1913) pour qui cette forme n'était pas antérieure au $\mathrm{III}^{\mathrm{e}} \mathrm{s}$.
FAITS ISOLÉS ${ }^{16}$

\section{FAIT D1}

Le fait archéologique D1 est situé en stratigraphie juste au-dessus de la couche 6 . Or, on a vu que cette couche, banc sableux stérile attribué à une inondation, vient buter sur le mur de l'habitat; elle recouvre également les couches résultant des travaux d'aménagement de l'état Il. Le fait D1 ne peut donc qu'être postérieur à cette phase d'agrandissement de l'habitat.

Le mobilier céramique est très abondant (cf. annexe, p. 99). Dans celui-ci, la sigillée, lisse ou décorée, est bien représentée. On trouve entre autres des Drag. 36, 35, Ritt. 14 (fig. 8, 8, 10 et 11), ainsi que des Drag. 29 et 37 (fig. 9, 1 et 3). Une anse d'amphore Dressel 20, estampillée P.I.R.PO (fig. 15, 15) figure également dans ce matériel. Quelques rares exemplaires de cette marque sont signalés par H. Callender (1965, p. 213, 1370-21), dont deux seulement pour la Gaule, à Poitiers et Lezoux. Elle ne semble pas mieux connue aujourd'hui.

Pour les éléments de datation, on retiendra la présence d'un Hermet 7 (fig. 8, 9) du Service F produit à La Graufesenque à partir de 90 (Vernhet, 1976) et un Drag. 37 à rattacher, par le décor de grands personnages (fig. 9,4), aux dernières productions (140-150) des ateliers de la Gaule du Sud (Vernhet, 1977). Le terminus posi quem de D1 peut donc être fixé au milieu du II $^{\mathrm{e}} \mathrm{s}$. de notre ère.

\section{FAIT D2}

Cette "fosse" n'a pu être située en stratigraphie. On peut, de plus, douter être en possession de l'ensemble du matériel recueilli : seule la céramique sigillée figure à l'inventaire (cf. annexe, p. 100) ${ }^{17}$. On remarquera néanmoins dans celle-ci un Ritt. 9 dont le décor en spirale (fig. 8, 3) caractérise les premières productions de cette forme dans les ateliers du Sud de la Gaule (Oswald, Pryce, 1966, p. 170).

16 J'ai volontairement écarté le fait $\mathrm{E} 6$ : il est reprèsenté par un seul tesson alors que celui-ci porte la mention "fosse à céramique"; il y a donc eu manifestement confusion et la précision apportée, "à l'ouest des murs extérieurs", doit renvoyer à l'un des deux dépotoirs (D1, D2) décelés dans les coupes. Dans le doute, il est apparu prudent d'éliminer cette observation.

17 Il est certain que l'ensemble du matériel issu de la fouille n'a pu être rassemblé : un Drag. 29, estampillé MELVVS FECIT, est mentionné dans le rapport de fouille; il a disparu de la collection. 

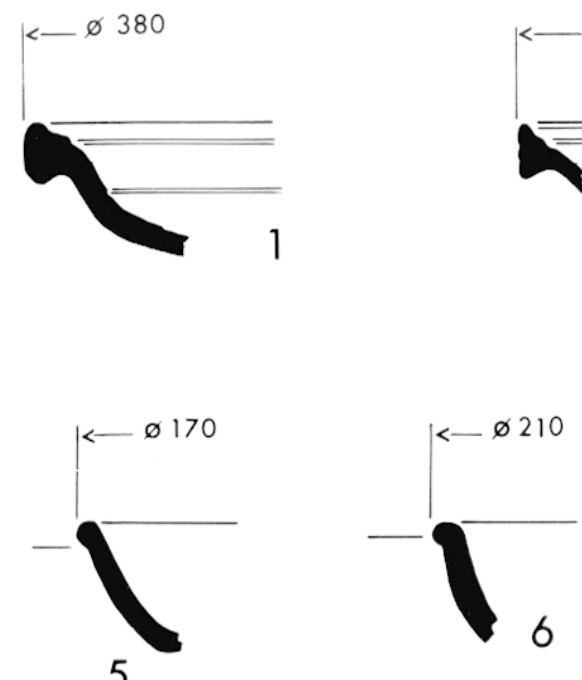

5 $\varnothing 180$

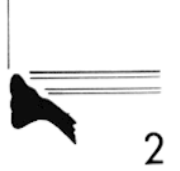

2
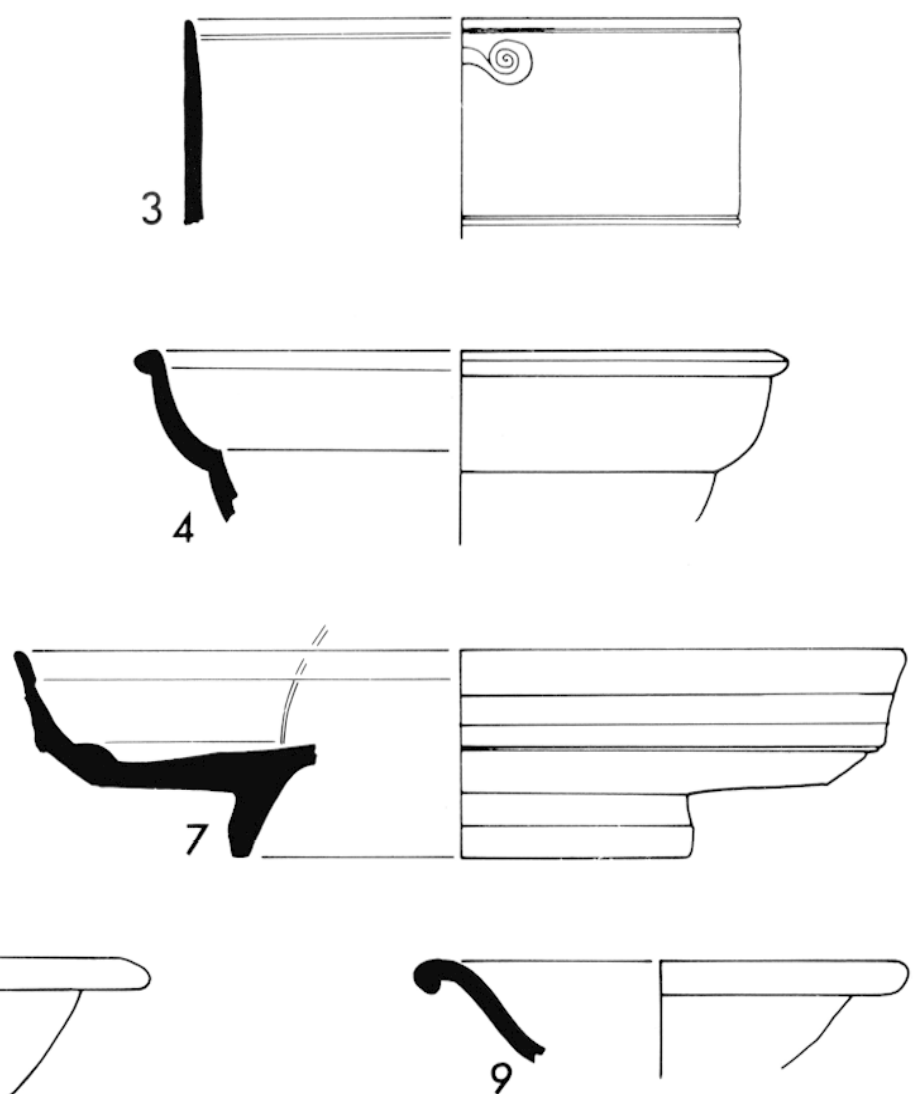

8
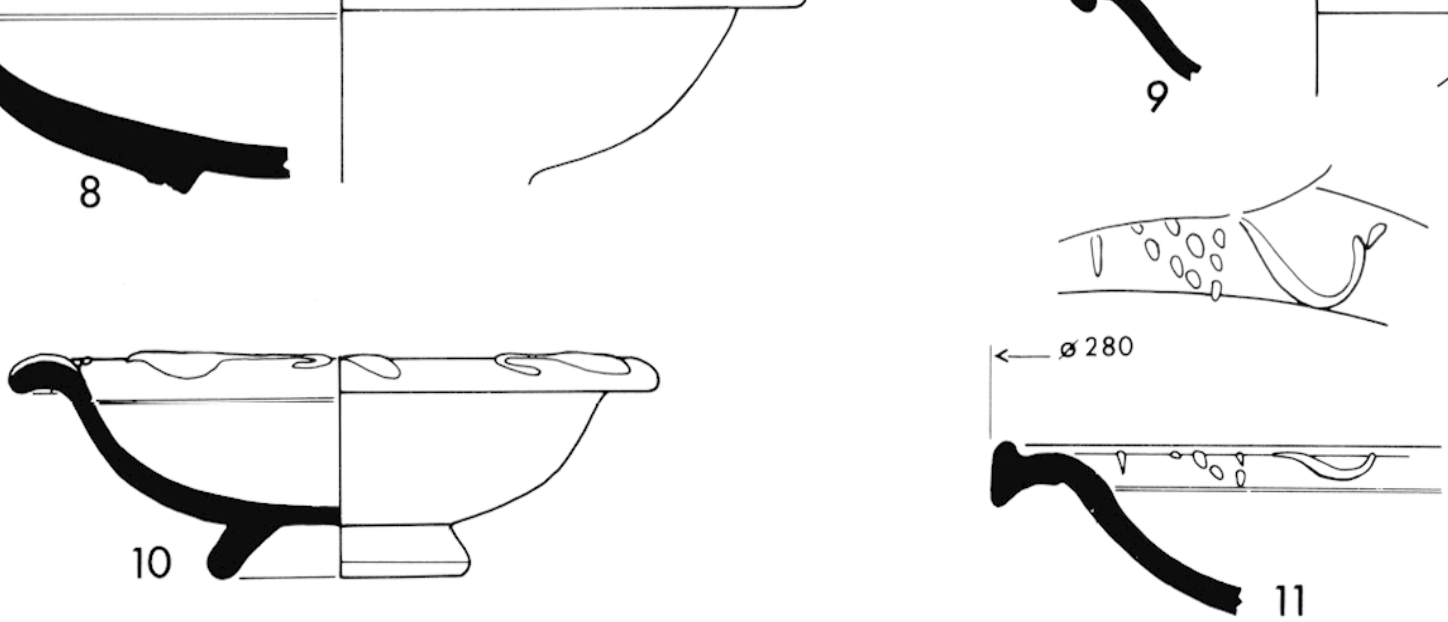

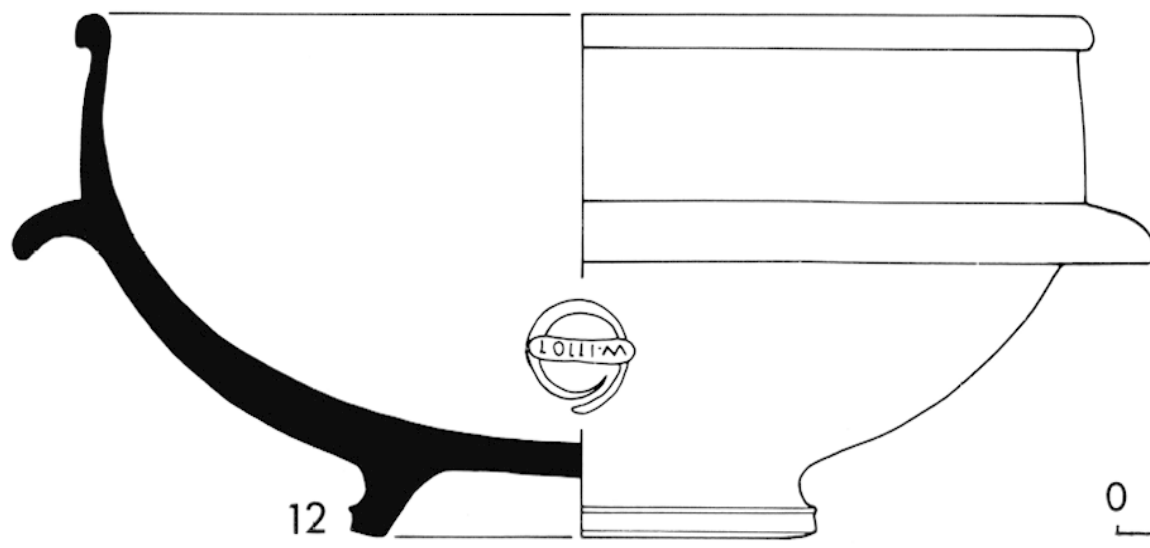

$5 \mathrm{~cm}$

Fig. 8 - Céramique sigillée lisse.

1, Goudineau 17 (B11-B15); 2, Goudineau 18 (H. S.); 3, Ritt. 9 (D2); 4, Drag. 27 (B3); 5 et 6, Drag. 18/31 (B3); 7, Drag. 15/17 (B3);

8, Drag. 36 (D1); 9, Hermet 7 (D1); 10, Drag. 35 (D1); 11, Ritt. 14 (D1); 12, Drag. 38 estampillée LOLLI.M (H. S.). 

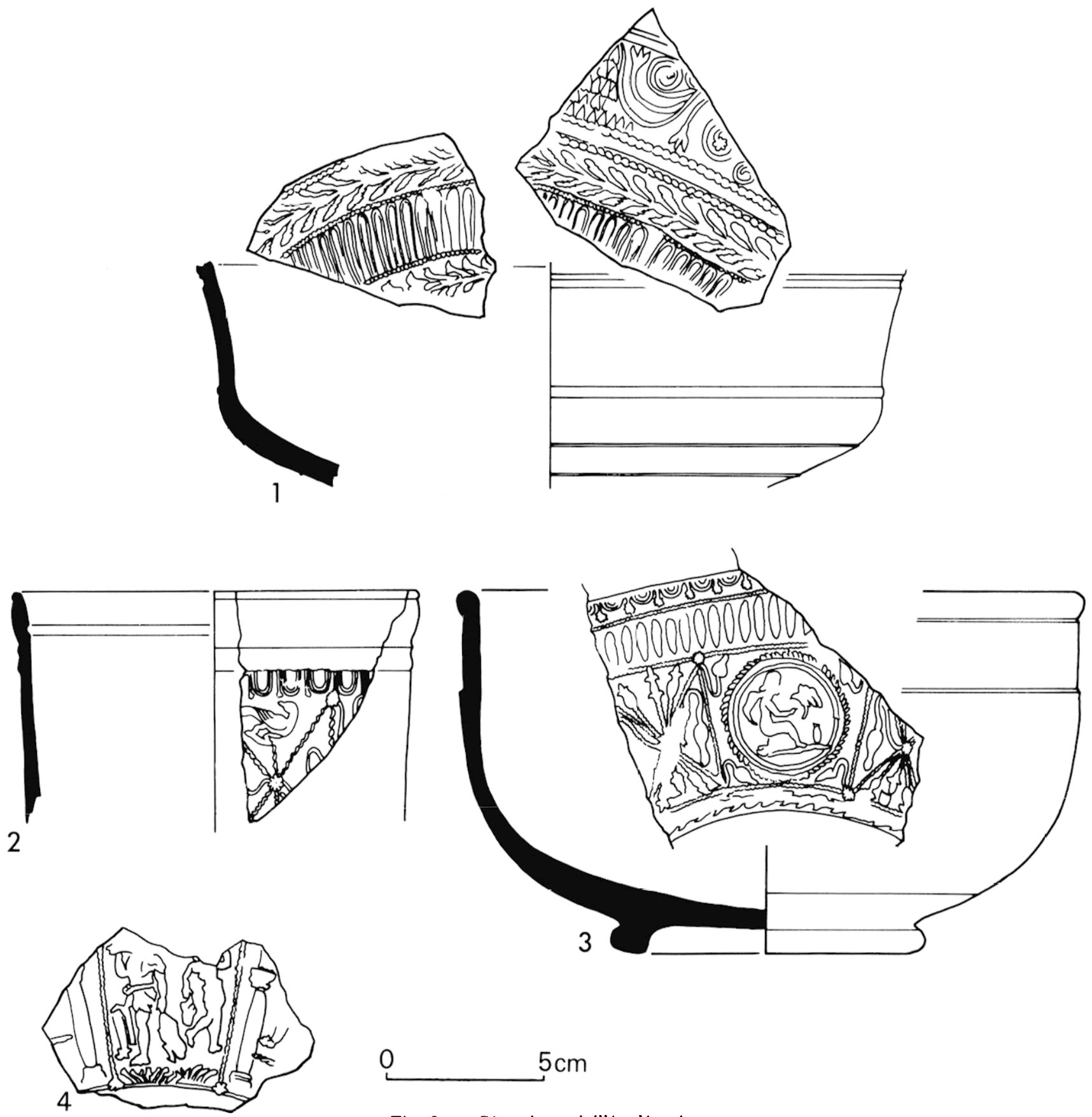

$5 \mathrm{~cm}$

Fig. 9 - Céramique sigillée décorée.

1, Drag. 29 (D1); 2, Drag. 30 (B1);3, Drag. 37 (D1); 4, Drag. 37 (D1).

FAIT D3

Les informations notées pour D3 le présentent comme un "dépotoir (situé) à proximité de l'amphore $2 »^{18}$, mais on ne possède aucun indice permettant de préciser cette proximité. En outre, le matériel qu'il renferme n'offre que des éléments de datation peu précis.

18 "Amphore 1 " devant désigner, selon toute vraisemblance, l'amphore cassée lors de la découverte.

\section{Puits}

C'est dans le puits que l'on a trouvé le mobilier archéologique le plus important en nombre et en diversité. Le matériel céramique comporte de nombreuses formes caractéristiques du $\mathrm{I}^{\mathrm{er}} \mathrm{s}$. (cf. annexe, p. 100) mais aussi du mobilier propre au $\mathrm{II}^{\mathrm{c}} \mathrm{s}$. : fragment de Drag. 38 des ateliers du Centre de la Gaule et céramique dite "allobroge" par exemple. Cette dernière, que l'on propose de dater, dans l'ètat actuel des connaissances, à l'intérieur d'une fourchette comprise entre le II $^{\circ} \mathrm{s}$. et la première moitié 

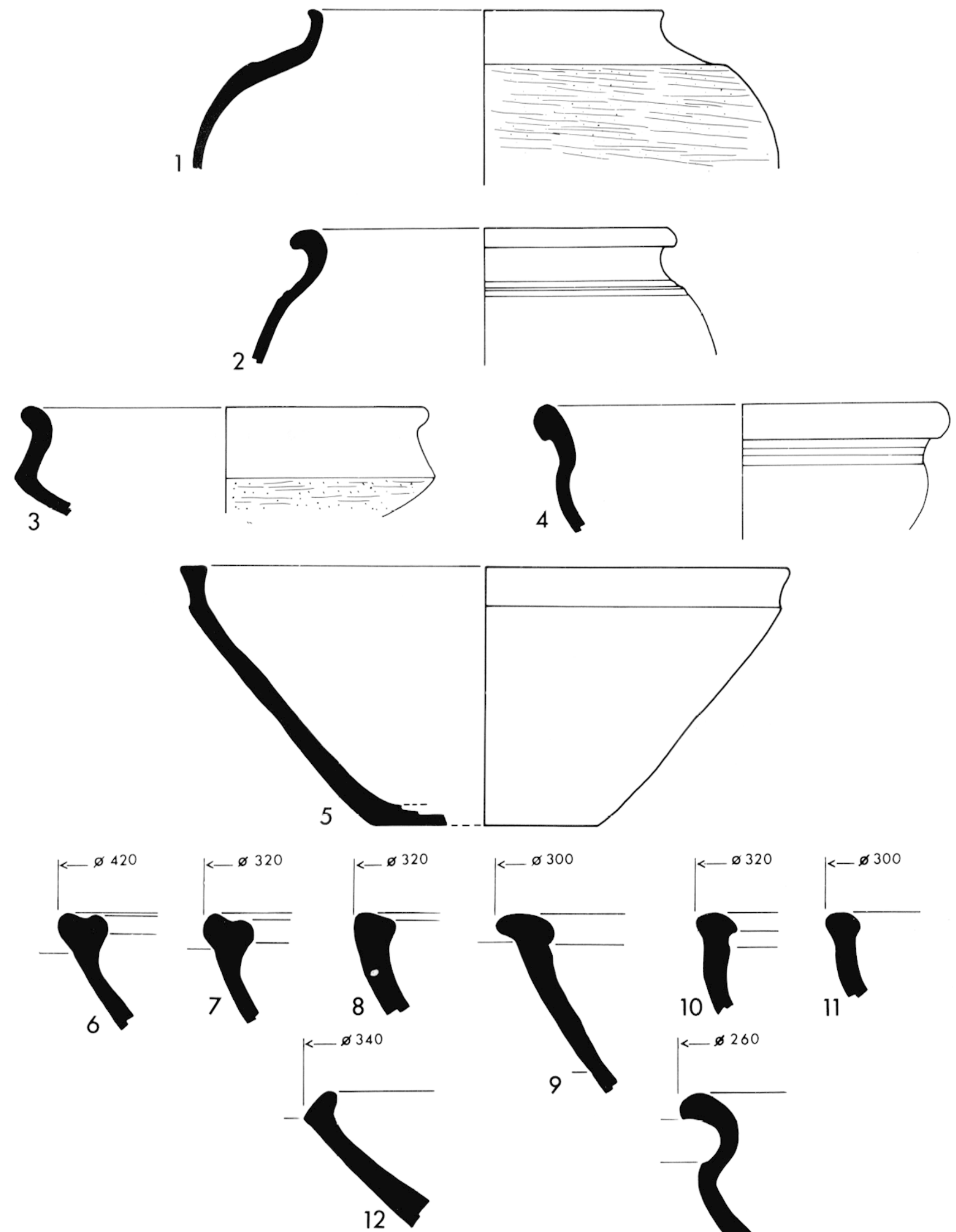

0 $5 \mathrm{~cm}$

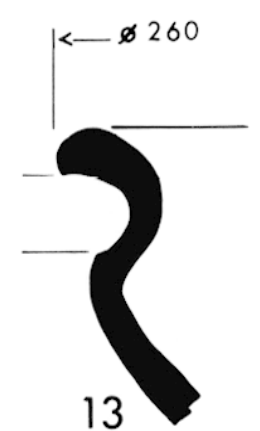

Fig. 10 - Céramique commune sombre.

1, pot ovoïde à épaule carénée (B1); 2 , pot ovoïde à épaule côtelée (D1); 3 , bol caréné (D1); 4, bol (puits); 5 à 13 : coupes (H. S. sauf 9 et $10, \mathrm{Dl})$. 
du III ${ }^{e}$ s. (Paunier, 1981, p. 40), est absente sur l'ensemble du site; elle est ici représentée par :

- un vase caréné, signé LVCIVS (fig. 12, 9);

- un vase ovoïde, signé NOSTER F(ecit)

(fig. 12, 7);

- un fond signé SVARADOF (ficina) ou SVARADO $F$ (ecit), avec $O F$ ou $F$ inversé (fig. 12,8).

Outre ce matériel céramique, on a également recueilli dans le puits un mobilier en métal, dont une serpette d'élagueur (fig. 18, 1), en verre, deux fragments de phiale côtelée (Isings 3 ) notamment, ainsi que plusieurs objets en bois :

- un petit bol, tourné, en buis (fig. 18, 2); 3) ;

- un peigne à deux rangées de dents (fig. 18 ,

- un axe de bobine de fil (?), tourné (fig. 18,4$)$;

- un grain d'enfilage (fig. 18,5 );

- unc baratte (?) à cinq branches rayonnantes (fig. 18, 6);

- un tonnelet (fig. 19) présentant un graffite illisible.

Ce mobilier, métallique, en verre ou en bois, présente peu d'éléments chronologiques. La serpette d'élagueur trouve des comparaisons dans le matériel de La Tène finale découvert sur la colline SainteBlandine à Vienne (Chapotat, 1970), mais F. Benoit (1947) a souligné la longévité de ce mobilier atypique. La phiale côtelée est caractéristique du $\mathrm{I}^{\text {er }} \mathrm{s}$. pour Morin-Jean (1913) et Isings (1957), mais on la retrouve, à Lyon par exemple (Odenhart-Donvez, 1983), jusqu'à la fin du $\mathbf{I I}^{\mathrm{e}} \mathrm{s}$. Pour le bois enfin, les seuls éléments de comparaison rencontrés concernent le peigne et le tonnelet : le peigne par la similitude de fabrication (limite de la dentition marquée par une mince ligne incisée) avec celui découvert au Mans dans des vestiges datés de la première moitié du Irer s. après J.-C. (collectif, 1984); le tonnelet, dans lequel on retrouve le procédé de fabrication observé lors d'une découverte dans un site daté des $\mathrm{I}^{\mathrm{er}}-\mathrm{II}^{\mathrm{e}} \mathrm{s}$. de notre ère (Viérin, Leva, 1961). Au regard du matériel céramique cependant, la date de comblement du puits ne parait pas antérieure au début du II $^{\mathrm{e}} \mathrm{s}$.

On notera également que, dans le puits, le comptage des formes et des tessons montre un avantage de la céramique commune claire sur la commune sombre. Cela tranche nettement avec ce qui peut être constaté partout sur le site sauf en D1 (cf. annexe, p. 99). En outre, le puits et D1 se rapprochent par la nature de leur mobilier : ils sont les seuls à renfermer du matériel produit au $\mathrm{II}^{\mathrm{e}} \mathbf{s}$., et plusieurs tessons recueillis en Dl ou dans le puits recollent entre eux. Il y a là un faisceau de présomptions qui invite à voir dans le comblement du puits et le dépôt Dl deux faits contemporains.

\section{LES APPORTS DE L'ETUDE DU MOBILIER}

L'étude du matériel archéologique recueilli sur le site du parking Lafayette apporte des enseignements de deux ordres: sur la chronologie de la naissance et l'évolution du quartier d'une part; sur le faciès du mobilier céramique présent à Grenoble d'autre part.

\section{LE FACIÈS DU MOBILIER CÉRAMIQUE}

L'étude de l'ensemble du matériel amène à constater la faible représentation du matériel sigillé produit dans les ateliers du Centre de la Gaule et le nombre important d'exemplaires en céramique dite commune restés sans comparaison ${ }^{19}$.

Pour ce qui concerne la céramique sigillée, le comptage des formes et des tessons montre une très forte supériorité en nombre des exemplaires produits dans le Sud de la Gaule. En incluant le matériel relevé hors stratigraphie, 140 exemplaires ont été comptabilisés. Dans ceux-ci, 6 restent de provenance indéterminée, 2 sont des productions italiques (fig. 8 , 1 et 2) et 5 seulement, dont un Drag. 38 estampillé LOLLI.M ${ }^{20}$ (fig. 8, 12), proviennent des ateliers du Centre de la Gaule. Le décompte des tessons marque la même disproportion: 263 fragments pour les ateliers du Sud de la Gaule, un pour ceux du Centre, 2 de provenance italique.

La deuxième remarque souligne l'originalité du matériel recueilli et suggère l'existence d'un lieu de production proche de Grenoble sinon dans la ville même. Certes, on retrouve dans le mobilier des exemplaires attestés à Lyon ou à Genève (Desbat $e$ t alii, 1979; Paunier, 1981): pots ovoïdes à épaule carénée (fig. 10,1) ou à épaule côtelée (fig. 10,2), pichets ovoïdes à une anse et col tronconique (fig. 12,2), vase en céramique fine, lissée, polie ou fumigée (fig. 12,3) pour la céramique commune sombre; pots ovoïdes à deux anses (fig. 13,1 et 2), cruches à col droit et lèvre bourrelet (fig. 15, 1),

19 Je m'en suis tenu au rapprochement des éléments caractéristiques ; certaines productions de céramique commune sont en effet trop atypiques pour permettre des rapprochements pertinents.

20 Cette estampille est celle de Lollivs, potier de Lezoux à une période estimée entre les règnes de Vespasien et d'Iladrien (Oswald, 1964, p. 167). 

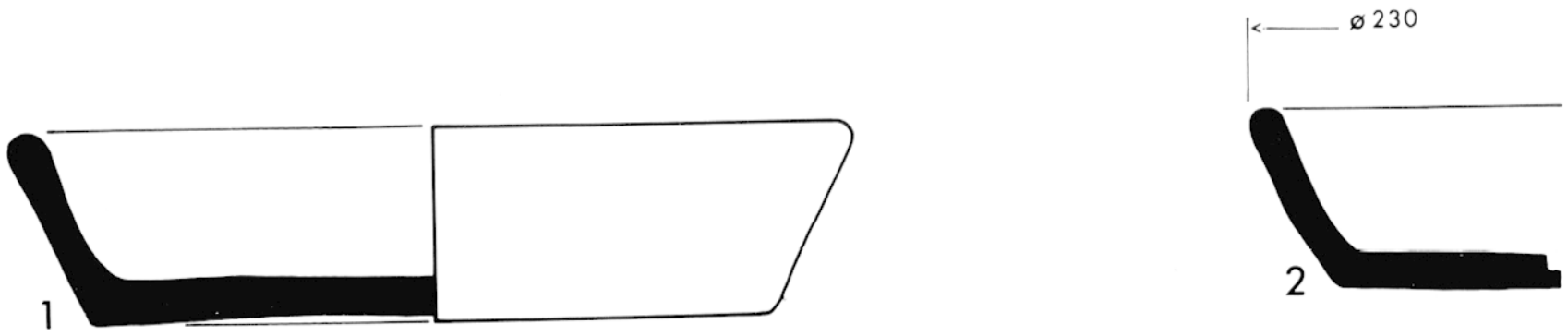

0

$5 \mathrm{~cm}$
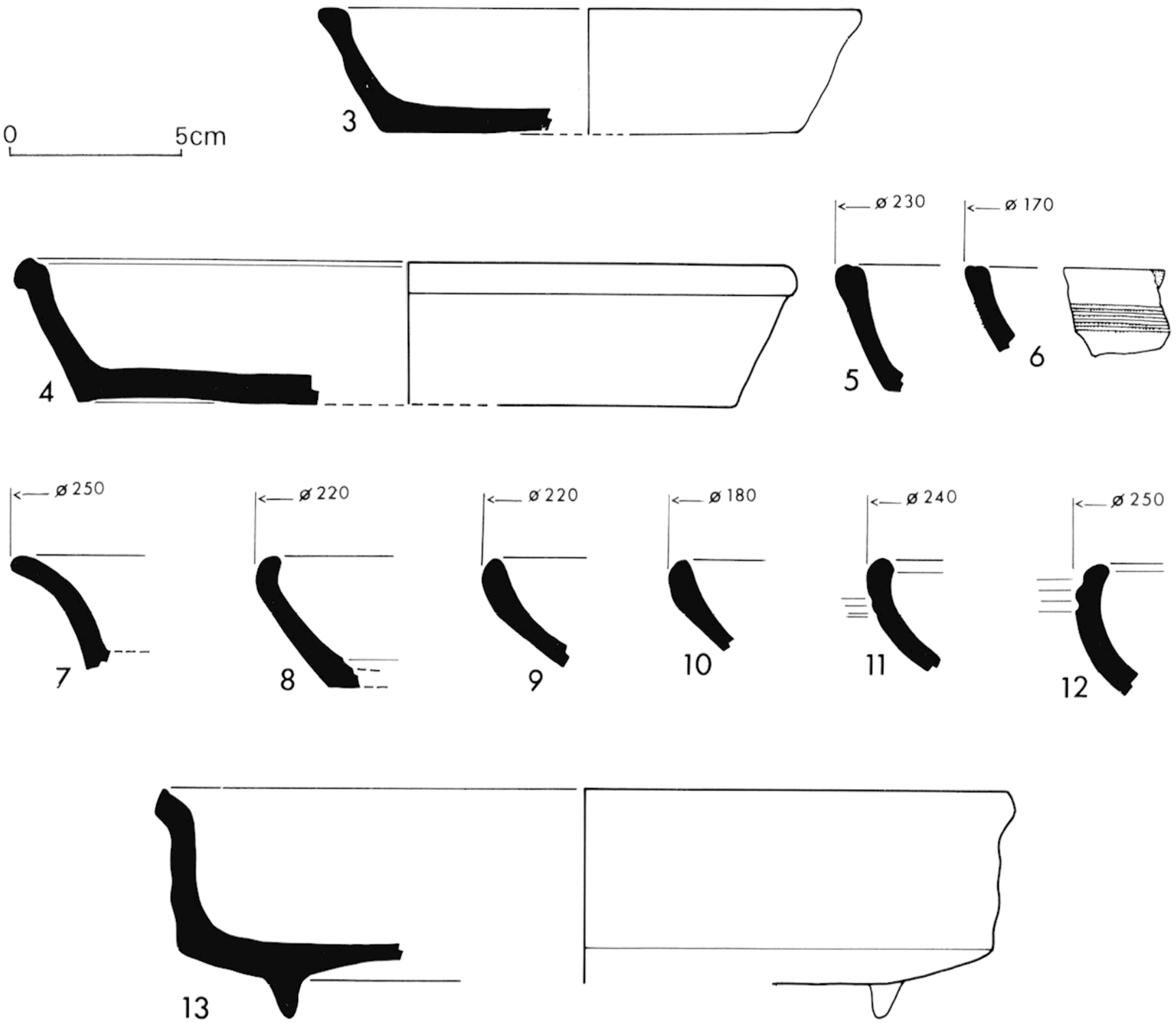

Fig. 11 - Céramique commune sombre : plats à cuire.

1 , (H. S.) et 2 (D1), à lèvre arrondie ; 3 , à lèvre triangulaire (D1); 4 , à bord déversé (puits); j̀ à 12 variantes $(5,8$ et $10:$ puits ; $6: \mathrm{D} 1 ; 7,9,11$ et $12:$ H. S.); 13 , tripode (D1).

mortiers à lèvre en bandeau, pendante, ou formant collerette rabattue (fig. 14, 7 à 12) pour la céramique commune claire. Il reste cependant un important matériel dont on ne retrouve l'équivalent ni à Lyon,
Vienne ou Genève ni même à Aoste (Isère) pourtant lieu de production important (Laroche, 1988) et peu éloigné de Grenoble.

L'essentiel de ce matériel a été recueilli dans des 

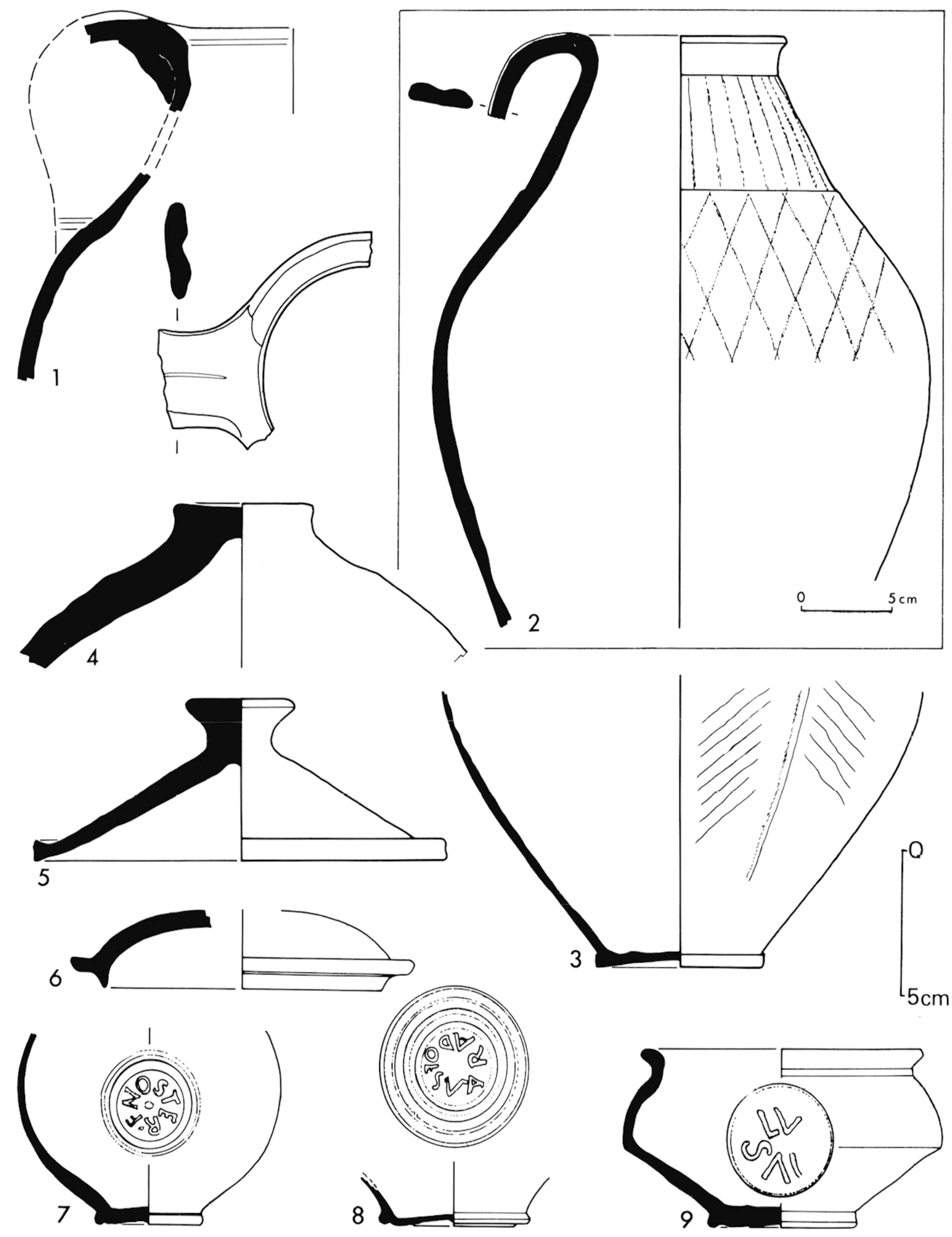

Fig. 12 - Céramique commune sombre.

1, pichet à lèvre en bandeau (puits); 2 , pichet à col tronconique (puits); 3 , fond de vase à panse côtelée (puits); 4,5 et 6 , couvercles (puits, B17 et D1); 7, 8 et 9 , céramique allobroge (puits). 
contextes datés à l'intérieur d'une fourchette large ( $\mathrm{I}^{\mathrm{er}}-\mathrm{II}^{\mathrm{e}} \mathrm{s}$.) mais la position stratigraphique de quelques exemplaires amène des précisions autorisant la classification chronologique suivante :

- au début du $\mathrm{i}^{\mathrm{er}} \mathrm{s}$. de notre ère, existe une production de céramique commune claire. Il s'agit d'assiettes au diamètre relativement important $(24 \mathrm{~cm})$, à lèvre triangulaire formant bord rentrant (fig. 14, 1);

- la seconde moitié du I $^{\text {er }}$ s. voit cette production d'assiettes à bord rentrant continuer tout en évoluant; la lèvre triangulaire disparaît pour laisser place à un bord moins anguleux (fig. 14,2).

On notera que cette production semble néanmoins limitée au regard de celle de la céramique commune sombre (cf. infra) : 6 exemplaires ont été inventoriés dont 2 seulement pour la série à lèvre triangulaire.

- $A u \mathrm{I}^{\mathrm{er}} \mathrm{s}$., on associera également les deux grandes séries de couvercles qui se dégagent des 21 exemplaires inventoriés : une série à lèvre retroussée et un bouton de préhension dégagé (fig. 12,5); une série au bouton de préhension nettement moins marqué (fig. 12,4).

- Dans la fourchette $\mathrm{I}^{\mathrm{er}}-\mathrm{II}^{*} \mathrm{~s}$., on inscrira le reste du mobilier, récolté pour la plus grande part dans le puits ou en D1:

\section{Céramique commune sombre}

- bols : caréné, à lèvre déversée (fig. 10,3 ), ou à col déversé décoré par lissage (fig. 10,4). Ces formes sont issues du répertoire de La Tène finale que l'on sait n'avoir jamais complètement disparu;

- coupes (ou marmites?) : toujours de grand diamètre (26 à $42 \mathrm{~cm})$. Les deux exemplaires trouvés en stratigraphie ont une lèvre débordante (fig. 10,9 et 10), mais de nombreuses variantes distinguent les exemplaires enregistrés hors stratigraphie (fig. 10,5 à 13$)$;

- assiettes (ou plats à cuire): relativement nombreuses (23 individus composent la série) mais souvent relevées hors stratigraphie. Les exemplaires recueillis présentent de multiples variantes (fig. 11,1 à 13). Parmi ceux récoltés dans des contextes datés, on distingue des modèles à bord arrondi, triangulaire ou déversé (fig. 11, 2, 3 et 4 ), à bord rentrant (fig. 11,8), à fond tripode (fig. 11, 13).

- pichet : un exemplaire trouvé dans le puits présente une lèvre en bandeau et une anse ruban (fig. 12,1);

- couvercle: aux deux grandes séries déjà notées (cf. supra), s'ajoute un unique exemplaire bien distinct par sa pâte, à l'aspect extérieur noir, et son pied annulaire (fig. 12,6). Ce type de couvercle est souvent associé à la céramique allobroge (Dangréaux, Jospin, 1986).

\section{Céramique commune claire}

- pots ovoides (avec anse?) au col peu marqué et à lèvre déversée (fig. 13,3);

- pichets aux nombreuses variantes, tant dans la forme générale que dans la lèvre. Six exemplaires (fig. 13,4 à 9) proviennent du puits; tous offrent un profil différent, l'un d'eux possédant même un bec verseur;

- cruches au col souvent évasé (fig. 15,2). Un exemplaire attire l'attention avec une embouchure en cupule (fig. 15,3) rencontrée à Camulodunum (Colchester) dans des niveaux du milieu du $\mathrm{I}^{\text {er }} \mathrm{s}$., mais, semble-t-il encore inconnu en Gaule (Sénéchal, 1975 , p. 96 et 98 );

- amphorettes : neuf exemplaires, tous recueillis dans le puits; ils présentent la même pâte, bistre, mais se différencient par la forme de leurs lèvres (fig. 15, 4 à 12).

On peut encore classer dans la céramique commune claire par leur type de cuisson en mode $\mathrm{A}^{21}$ quelques pièces particulières :

- deux coupes à lèvre tombante (fig. 14,3 et 4); le fond, plat, présente des traces de décollage "à la ficelle"; la pâte est claire mais de couleur bistre:

- une coupe aver collerette en milieu de panse (fig. 14,6 ) ; la pâte, rouge, contient quelques points de chaux. On notera la parenté de cette coupe avec la forme 44 en sigillée claire B (Darton, 1972);

- une coupe, à pâte claire, avec collerette sous la lèvre (fig. 14,5) rappelant la forme Curle 11 en céramique sigillée.

\section{LA CHRONOLOGIE DE L'AMÉNAGEMENT URBAIN}

L'étude du mobilier archéologique amène à formuler trois remarques relatives à la chronologie de l'aménagement urbain :

1: aucun matériel découvert à l'intérieur du bâtiment n'est inconnu au $\mathrm{I}^{\mathrm{er}} \mathrm{s}$. de notre ère;

2 : le puits et le "dépotoir" D1 sont les seules structures dans lesquelles il a été recueilli du matériel produit à partir du $11^{\mathrm{e}} \mathrm{s}$;

21 Les modes de cuisson sont ceux définis par Picon (1973); mode A : cuisson réductrice, post-cuisson oxydante; mode $B$ : cuisson et post-cuisson réductrices; mode $C$ : cuisson et post-cuisson oxydantes. 

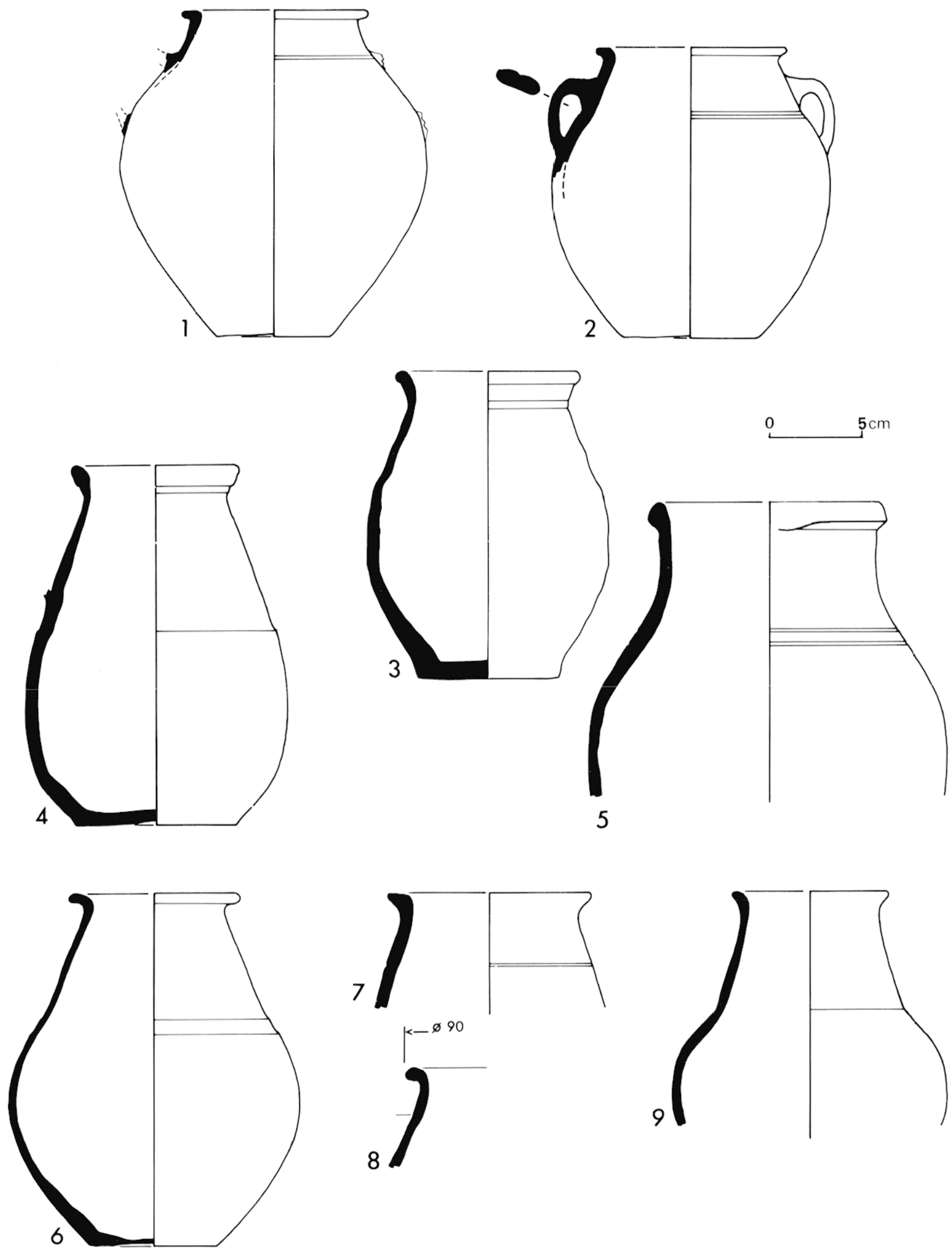

Fig. 13 - Céramique commune claire.

1 et 2 , pots ovoïdes à deux anses (puits); 3 , pot ovoide (avec anse ?) (puits); 4 à 9 , pichets (puits). 

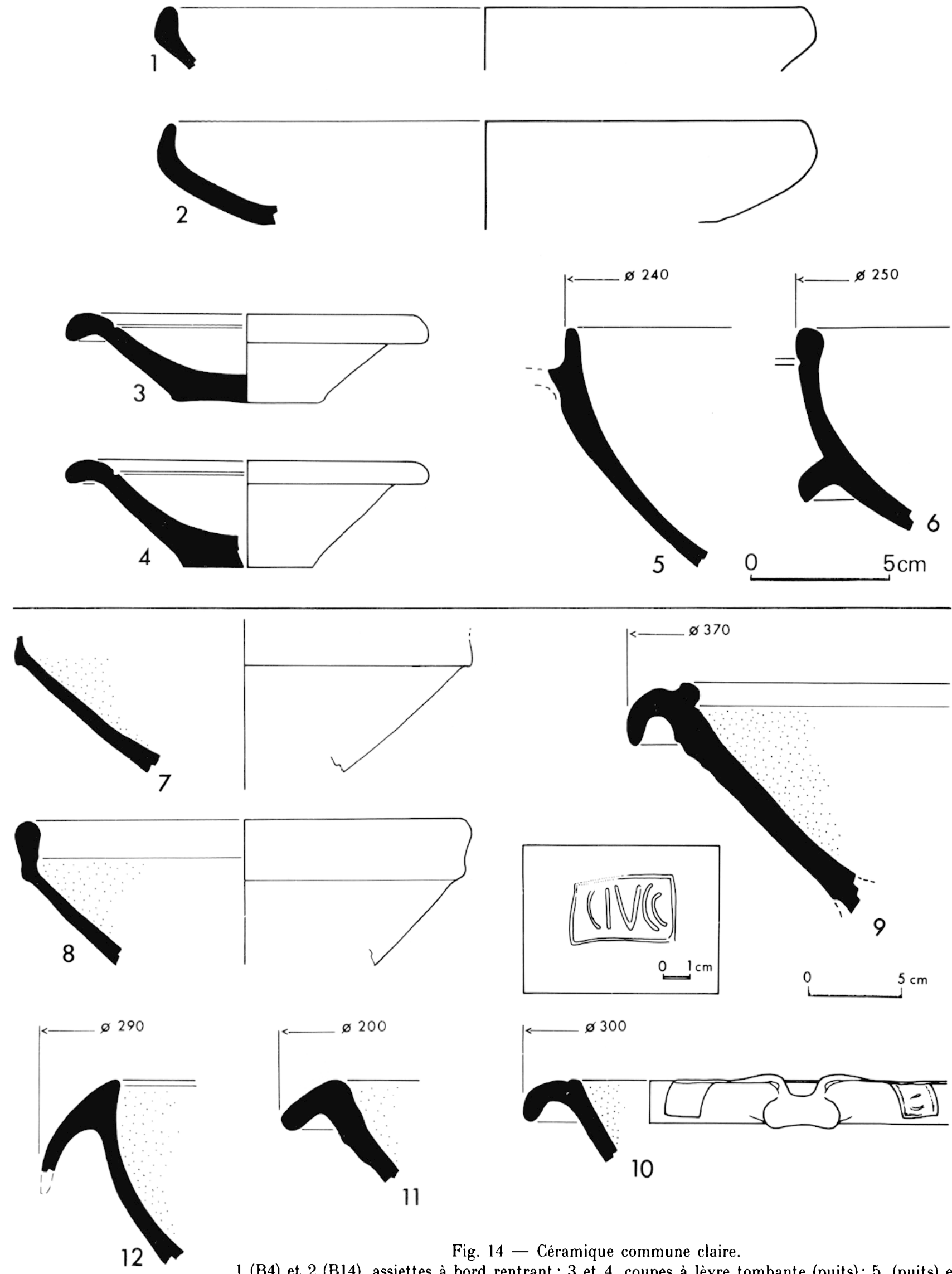

11

Fig. 14 - Céramique commune claire.

1 (B4) et 2 (B14), assiettes à bord rentrant; 3 et 4 , coupes à lèvre tombante (puits); 5 , (puits) et 6 (D1), coupes à collerettes; mortiers : 7 (B1) et 8 (D1), à lèvre en bandeau; 9 (puits), 10 (H. S.) et 11 (puits), à lèvre tombante; 12 (H. S.), à lèvre formant collerette. 

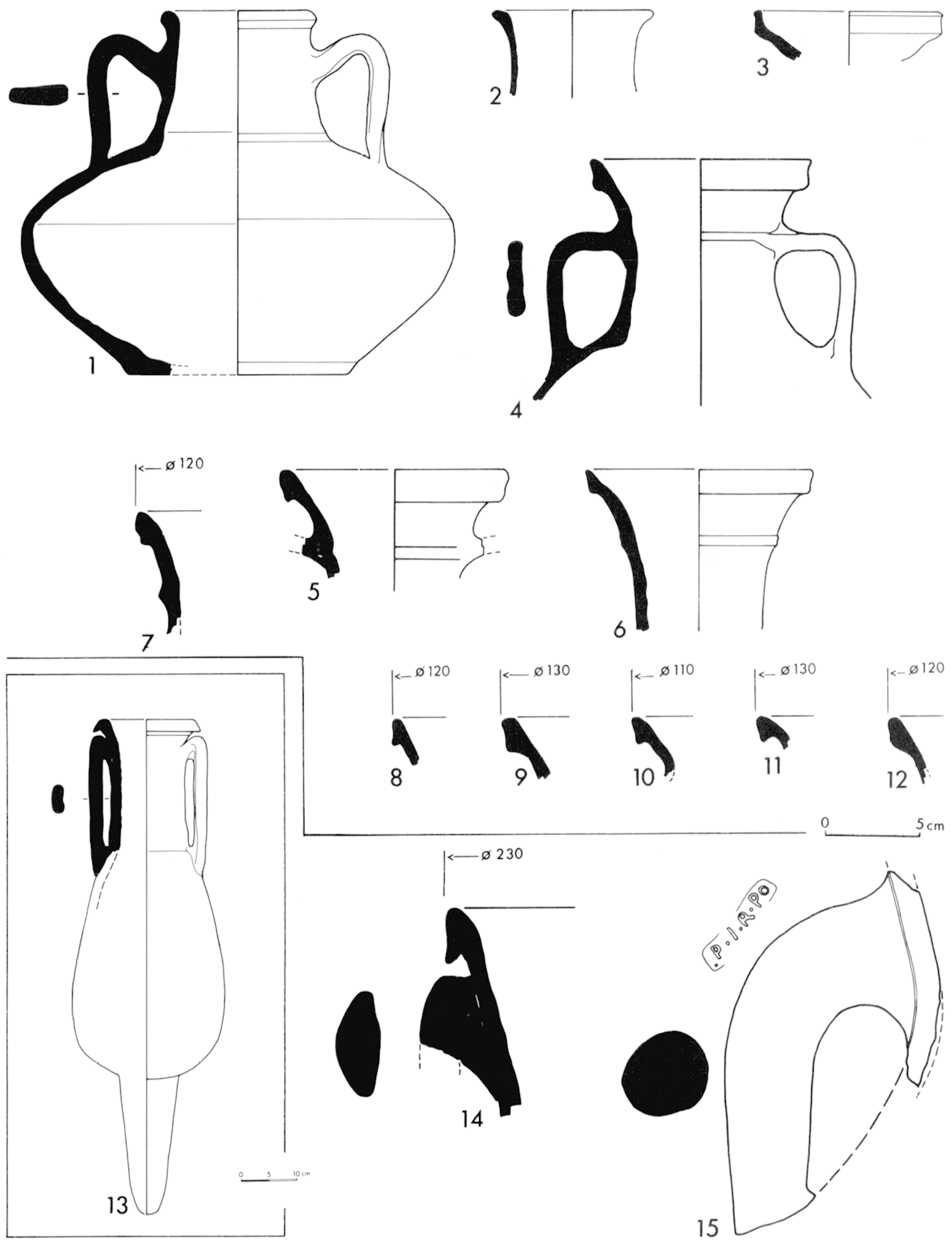

Fig. 15 - Céramique commune claire.

1 , cruche à col droit (D1); 2 , cruche à col évasé (puits); 3 , cruche à embouchure en cupule (D) ; 4 à 12, amphorettes (puits). Amphores. 13 (amphore 2) et 14 (puits) : amphores Beltrán $1 \mathrm{la} ; 15$, anse de Dressel 20 estampillée P.I.R.PO (D1). 
3: le tesson le plus ancien est situé en altimétrie à un niveau supérieur (couche 4) aux couches de destruction de l'habitat.

Cette dernière remarque confirme l'interprétation donnée à la couche 4 par les observations de terrain : il s'agit bien d'un remblai. Les deux autres soulignent le hiatus chronologique qu'offrent le matériel dans l'habitat d'une part, le puits et D1 d'autre part.

Il est possible dès lors, en tenant compte des lermini proposés pour chaque fait archéologique, d'envisager le schéma suivant quant à l'aménagement urbain :

\section{L'OCCUPATION PRIMITIVE}

Elle a pour témoin la couche 7. C'est la première couche dans laquelle on peut noter la présence de matériel archéologique; elle tranche en cela avec la couche 8 , substrat de limon sableux archéologiquement stérile, immédiatement inférieure. Cette première occupation ne peut pas avoir eu lieu avant le début de l'ère chrétienne, ainsi que l'avait fait entrevoir la fouille de la rue de la République (Bocquet, 1963).

\section{L'ÉVOLUTION DE L'HABITAT}

L'installation, puis la transformation de l'habitat s'effectue tout entière à l'intérieur du $\mathrm{I}^{\text {er }} \mathrm{s}$. après J.-C.

\section{L'état I}

L'édification du premier habitat suivrait de peu, si elle ne fût contemporaine, cette première occupation.

Le bâtiment se présente alors sous la forme d'un rectangle; les divisions intérieures composent au moins quatre pièces, au sol de terre battue, et dessinent un ensemble organisé autour d'un espace (cour?). Les murs (dont on ne peut dire s'ils supportaient une architecture de terre ou s'ils étaient entièrement maçonnés) sont appareillés et reposent sur un soubassement liè au mortier et un radier. L'accès à l'habitat est marqué par deux massifs maçonnés.

Cette première construction est élevée dans la première moitié du $\mathbf{I}^{\mathrm{er}} \mathrm{s}$., compte tenu des indices de datation relatifs à l'état $I I$.

\section{L'ètat II}

La phase d'agrandissement et de restructuration de l'habitat serait en effet achevée au milieu du $\mathrm{I}^{\mathrm{er}} \mathrm{s}$. : c'est le terminus ante quem admis pour le décor d'enduit peint qui vient recouvrir quelques pièces; c'est également la date attribuée au tesson le plus récent découvert dans la couche de destruction de l'habitat.

Il y a une transformation profonde de l'habitat : augmentation de son emprise au sol, recomposition interne, enrichissement du décor. La façade nordouest est prolongée, l'espace central supprimé au profit de pièces créées en élevant des murs de terre; les sols restent de terre battue mais plusieurs pièces reçoivent des peintures murales.

\section{L'élat III}

Il marque la dernière phase d'occupation de l'habitat. Cette phase n'est mise en évidence que par l'aménagement d'une structure supplémentaire dans la pièce 2. Mais, il faut noter que cette même pièce ne reçoit pas de décor peint; il peut donc s'agir d'une pièce réservée dès la conception de l'état II à une quelconque tâche utilisant cette structure. Dans ce cas les états II et III pourraient être contemporains.

Une autre hypothèse est liée à la chronologie de la couche présentée comme le résultat d'une inondation. Cette couche est postérieure à l'état II : elle vient recouvrir les vestiges de cette phase d'aménagement. On ignore cependant sa position dans le temps par rapport à l'état III; antérieure à cette dernière phase, on pourrait voir en celle-ci la trace d'une réutilisation momentanée de l'habitat avant l'abandon définitif précédant sa destruction.

Il reste que cette destruction intervient avant la fin du $\mathrm{I}^{\mathrm{er}} \mathrm{s}$. Aucun matériel céramique produit au ${ }{ }^{\mathrm{e}} \mathrm{s}$. n'a été retrouvé dans les couches de démolition.

\section{L'AMÉNAGEMENT DE L'ESPACE}

Dans l'espace, ne subsisterait alors que le puits, si l'on veut bien admettre qu'il fût contemporain de l'habitat ${ }^{22}$. La couche 5 , qui porte quelques vestiges de l'activité humaine, atteste d'ailleurs que le quartier reste fréquenté.

Rue de la République, on a trouvé dans cette couche 5 quelques fragments de fonds allobroges (Bocquet, 1963). On peut donc proposer pour cette couche un terminus post quem au début du $\mathrm{II}^{\mathrm{e}} \mathrm{s}$.

Entre le milieu du $\mathrm{II}^{\mathrm{e}} \mathrm{s}$. (terminus post quem de D1 et du puits) et la fin de ce même siècle (absence de matériel céramique produit au-delà de cette période)

22 L'absence d'observations stratigraphiques empêche de savoir si le matériel le plus ancien se situait aux niveaux les plus bas ou si, au contraire, il y avait brassage du matériel. 


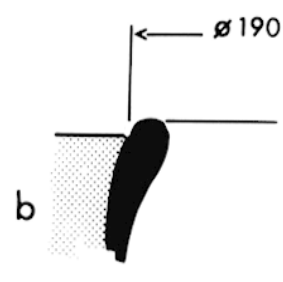

1
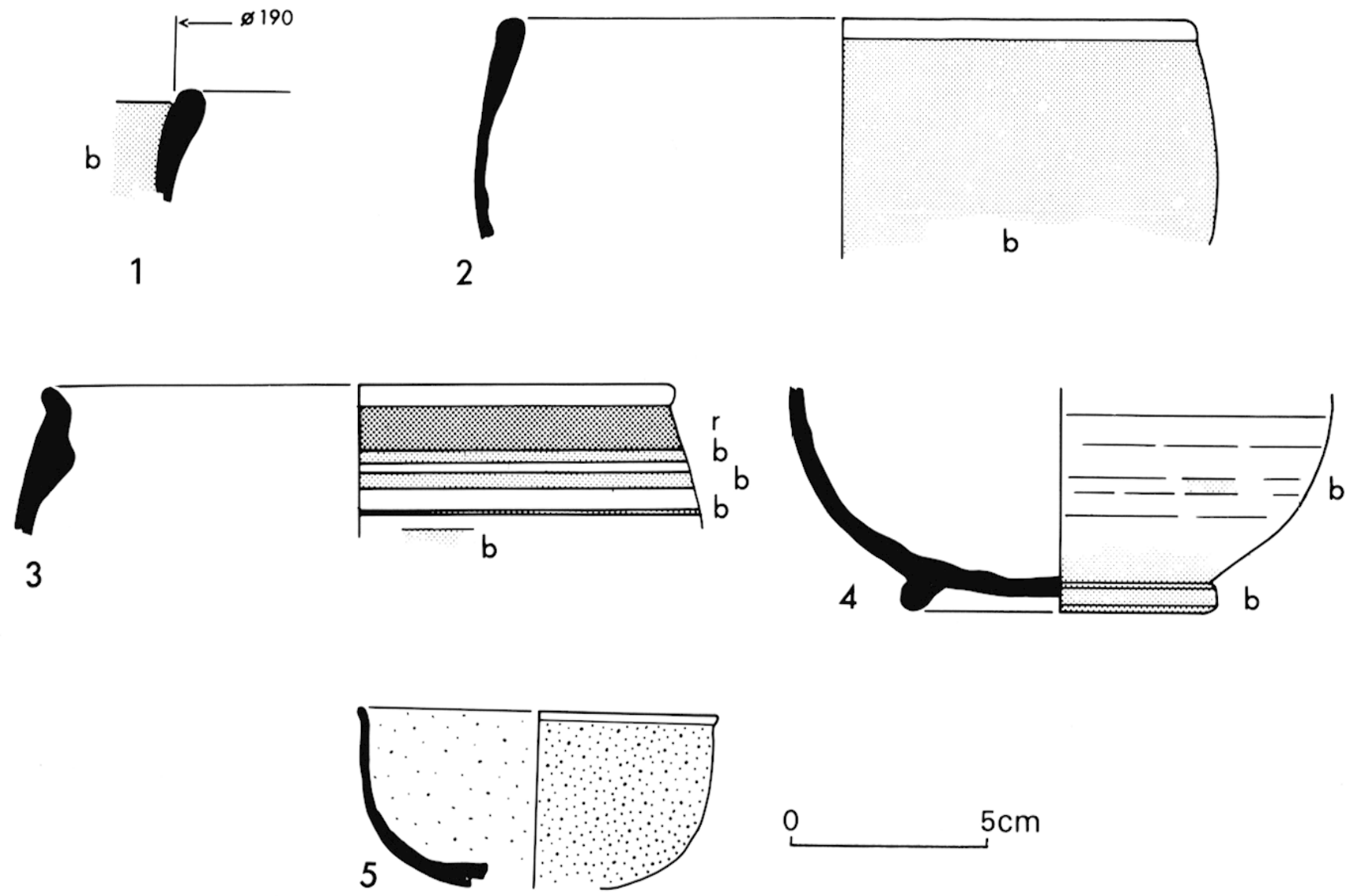

Fig. 16 - Céramique peinte.

1 (D4) et 2 (B1), bol de Roanne; 3, bord de bol à renflement interne (H. S.); 4, bol (B20). Céramique à parois fines. 5 , bol sablé (B3).

viendrait alors une phase de travaux ${ }^{23}$. Ces travaux conduiraient à l'arasement du puits et à son comblement; en même temps seraient remblayés les niveaux d'habitat.

C'est sur ces remblais que viendrait alors s'implanter la seconde phase de construction reconnue rue de la République et à laquelle sont associés des vestiges de céramique sigillée claire $B$ inconnue jusque-là sur le site ${ }^{24}$.

\section{***}

La fouille du parking Lafayette et l'étude de son mobilier archéologique révèlent donc l'existence

23 Si la monnaie de Faustine la Jeune découverte rue de la République vient bien de la couche 4 , c'est vers 170 qu'il faut fixer le terminus post quem de cette phase de travaux.

24 La sigillée claire $B$, absente du matériel découvert au parking Lafayette, apparaît dans la stratigraphie de la rue de la République. Un exemplaire est notamment enregistré dans la couche 3 (cf. fig. 2). Ce matériel figure dans les réserves du musée Dauphinois à Grenoble mais n'a pas fait, à ce jour, l'objet d'étude. d'un matériel céramique original et apportent des précisions dans la datation de la naissance et l'évolution de ce quartier de Grenoble antique.

Pour le premier de ces deux points, on notera que, à côté de la sigillée, de la céramique peinte, des types à parois fines, allobroge ou d'autres reconnus par ailleurs, on a pu dégager des séries que l'on peut croire rattachées à une production locale.

Pour la céramique commune sombre, comme pour la commune claire, on retiendra les nombreuses variantes rencontrées à l'intérieur d'une vaisselle que l'on peut qualifier "de cuisine" (assiettes ou plats à cuire, coupes ou marmites), "de table" (bols, assiettes, pichets, cruches) ou de conservation (pots et couvercles).

La datation de ces différentes productions devra être précisée par d'autres découvertes. Retenons que, pour l'heure, la plupart d'entre elles s'inscrivent à l'intérieur d'une fourchette comprise entre le début du $\mathrm{I}^{\mathrm{er}} \mathrm{s}$. et la fin du $\mathrm{II}^{\mathrm{e}} \mathrm{s}$.; l'existence d'une production d'assiettes en céramique commune claire est cependant attestée dès le $\mathrm{I}^{\text {er }} \mathrm{s}$. de notre ère.

Quant à l'histoire du quartier, on peut, en 


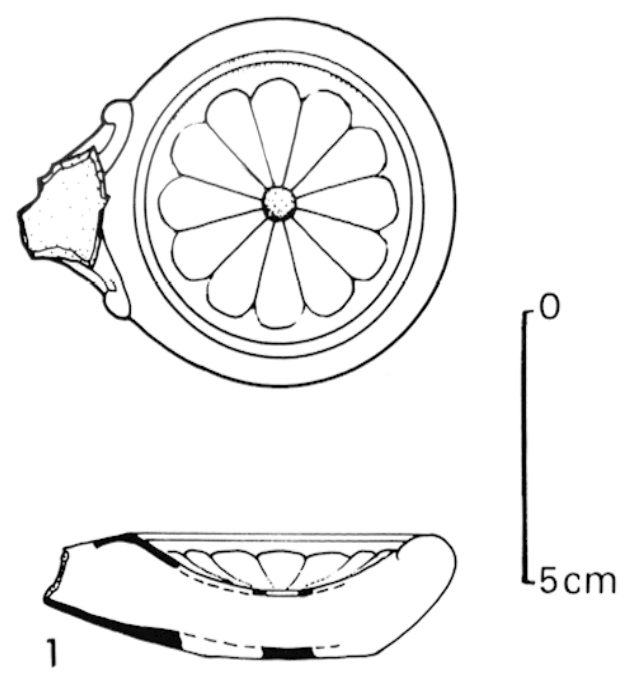

Fig. 17 - Céramique.

1 , lampe à volutes $(\mathrm{B} 8)$

Verre. 2, calice (B9).

Poids de suspension (pesons de tisserand). 3 à 12 (B7), décor, graffites et estampilles sur pesons.
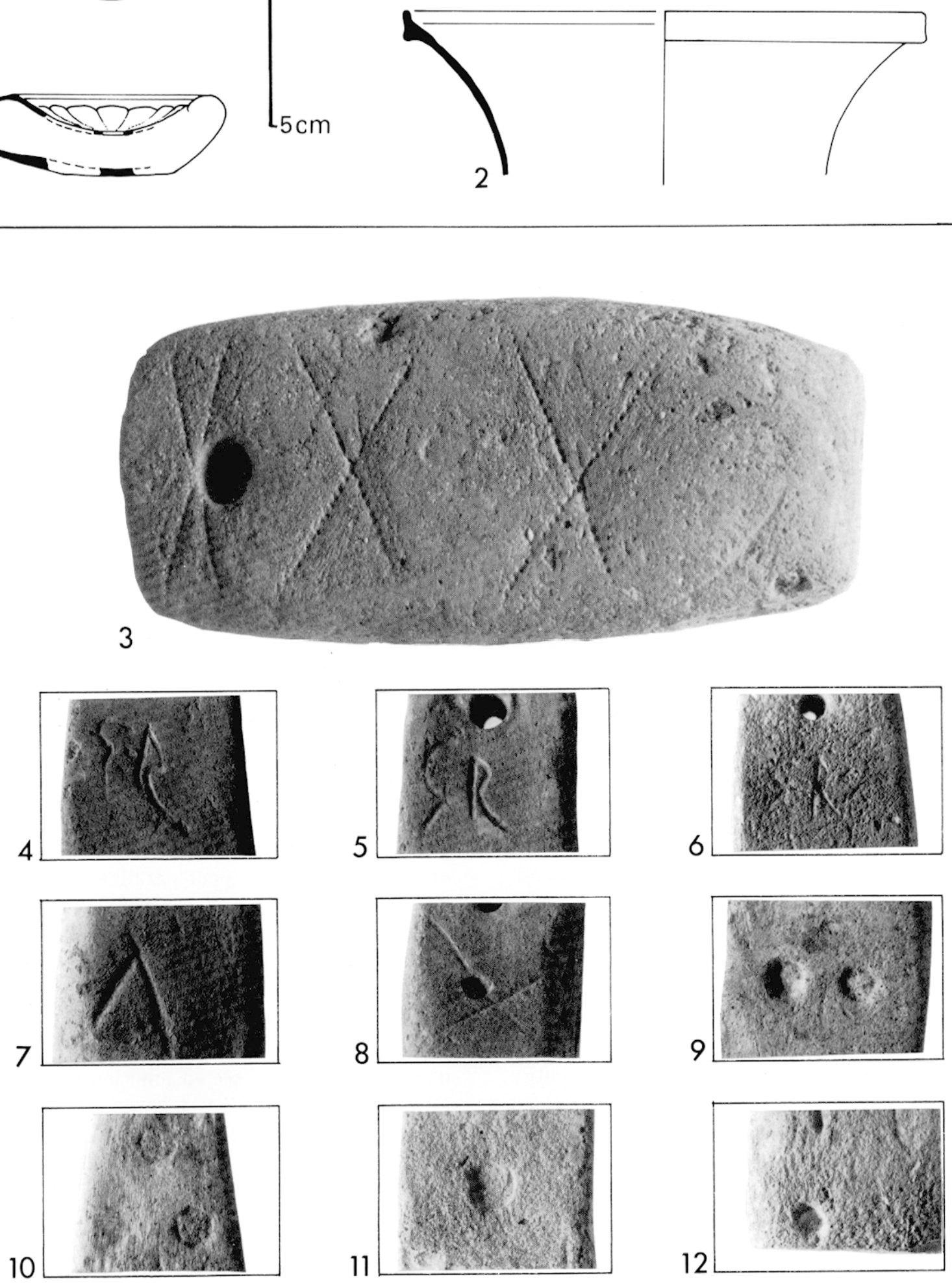


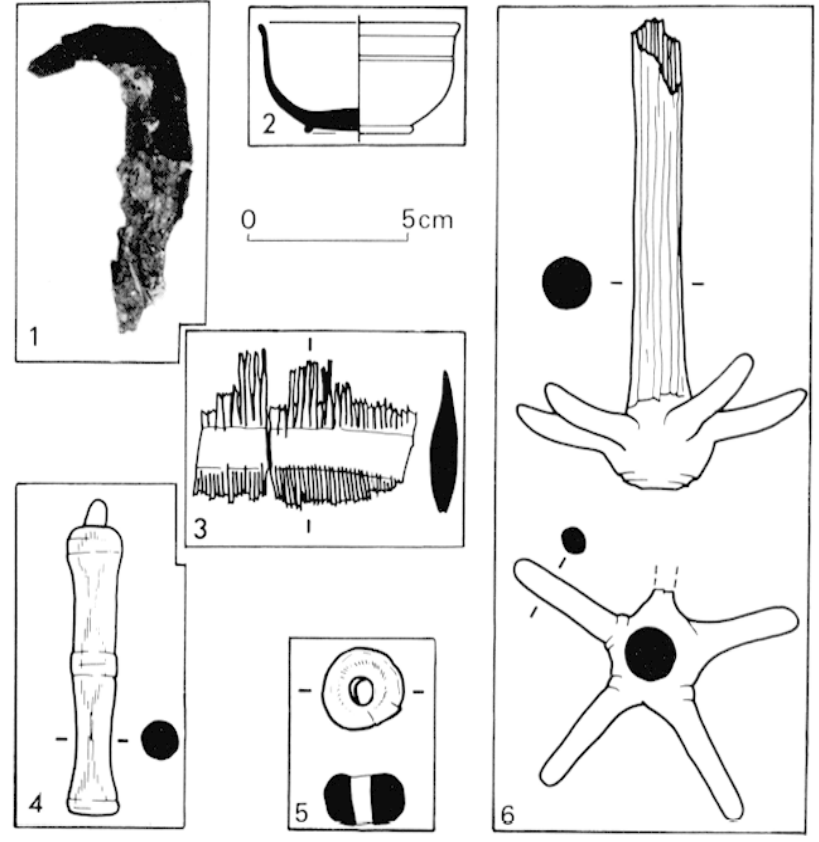

Fig. 18 - Mobilier métallique.

1 , serpette d'élagueur (puits).

Objets en bois. 2 , bol en buis; 3 , peigne; 4 , axe de bobine?; 5 , grain d'enfil.ge; 6 , baratte? (puits).

Fig. 19 - Objet en bois : tonnelet (puits).

tenant compte des enseignements apportés par la fouille de la rue de la République, la résumer de la manière suivante :

- le début du $\mathrm{I}^{\mathrm{er}} \mathrm{s}$. de notre ère voit s'édifier les premiers habitats. C'est la première occupation sédentaire du quartier. On en retrouve les vestiges à la fois rue de la République et sur le site du parking Lafayette;

- à la moitié de ce même siècle, l'habitat est transformé. Au parking Lafayette on est en présence d'un bâtiment agrandi, repensé dans son organisation, enrichi par son décor;

- durant la seconde moitié du $\mathrm{I}^{\mathrm{ar}} \mathrm{s}$., les premiers habitats sont désertés, probablement à la suite d'une inondation. Un puits (contemporain des premières constructions?) resterait néanmoins exploité ;

- la seconde moitié du $\mathrm{II}^{\mathrm{e}} \mathrm{s}$. est marquée par d'importants travaux de remblaiement. Le puits est arasé puis comblé en même temps que sont recouverts les premiers habitats. Sur ces remblais viennent alors s'élever les constructions observées rue de la République;

- à la fin du in' s., l'édification des remparts
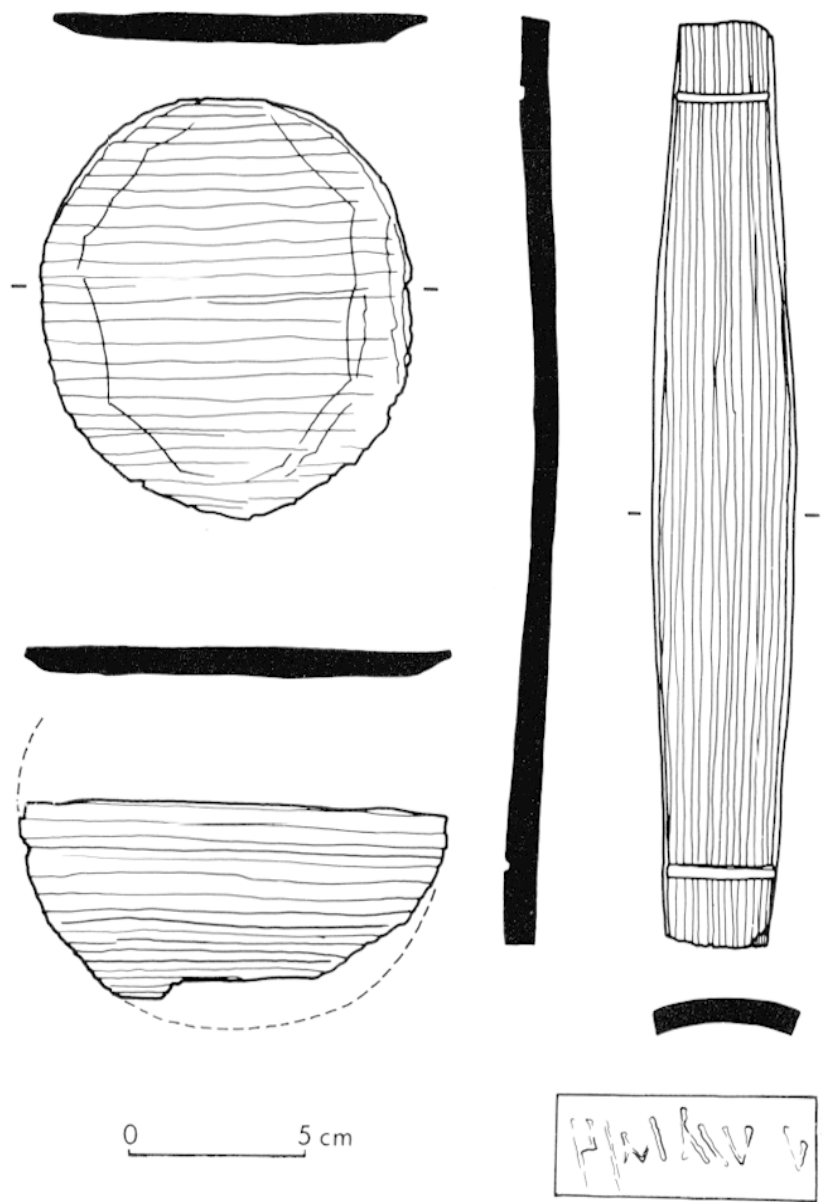

(cf. supra, note 5) vient détruire cette seconde phase de construction.

Les résultats de la fouille amènent enfin à poser la question de savoir s'il y eut ou non, à Grenoble, un réseau urbain organisé.

Si l'on se réfère à l'ordonnancement général des structures mises au jour rue de la République et au parking Lafayette (fig. 1, 2), l'éventualité n'est pas à exclure. L'hypothèse peut paraitre hardie au regard du peu de vestiges découverts. On remarquera toutefois que la cathédrale, place Notre-Dame (fig. la) est orientée de la même manière que les structures anliques. S'il existe, ce réseau est mis en place très tôt: dès le début du $\mathrm{I}^{\text {er }} \mathrm{s}$., avec les premières constructions. En ce cas l'implantation n'aurait pas été réalisée en fonction d'axes nord-sud et est-ouest, mais l'on sait maintenant ce qu'il convient de penser d'un a priori qui a longtemps influencé les études urbaines (Le Gall, 1975).

Faut-il alors lui associer le "pavage de galets" relevé ici ou là par H. Müller (1930, passim) à l'intérieur de la ville actuelle et retrouvé près de l'angle Al du bâtiment? On sait qu'à Saint-Romain- 
en-Gal (Desbat et alii, 1983, p. 8) la voie est-ouest augustéenne et à Annecy le premier état du forum ${ }^{25}$ ne se présentent pas autrement. La réponse ne peut être apportée que par des observations à venir.

Il serait de même souhaitable de pouvoir assurer le caractère fluviatile prêté à la couche 6 . On disposerait ainsi d'un critère d'appréciation pour juger la décision qui a conduit à exhausser le niveau d'occupation. S'agissait-il de protéger la ville contre les risques d'inondation? Une telle entreprise parait alors vaine : l'histoire de la ville offre assez d'exemples d'inondations spectaculaires (Blanchard, 1935) jusqu'à ce que soient édifiés les quais bordant l'Isère. S'agissait-il de remodeler la ville en fonction d'aspirations nouvelles? On entre ici dans le domaine de la pure conjecture.

Il n'en demeure pas moins que la réalité d'une politique urbaine s'accomoderait assez avec ce que l'on connaît de Grenoble pour l'Antiquité (Dangréaux, 1986). Si Cularo est nommé en 43 avant J.-C., rien ne montre qu'à l'époque l'agglomération est de celles qui comptent à l'intérieur du territoire allobroge. Or, à la fin du $I^{r}$ s. après J.-C., et peutêtre dès le II $^{\mathrm{e}} \mathrm{s}$., Grenoble est chef-lieu de cité à l'intérieur de la nouvelle province de Vienne et jusque-là Cularo tint fort probablement rang de vicus. En outre, l'agglomération tient un rôle administratif par son poste de péage du quarantième des Gaules, son activité religieuse se laisse deviner par nombre de dédicaces aux divinités et quelques piédestaux de statues invitent à penser que l'on ne se priva pas du décor urbain calqué sur le modèle romain. Le fait enfin qu'elle abrita plusieurs personnages ayant tenu des fonctions municipales et/ou sacerdotales tend à montrer combien l'évolution de l'agglomération dut être importante depuis la première mention de L. Munatius Plancus en 43 avant J.-C. Rien n'interdit donc qu'elle ait connu avec bien d'autres un aménagement urbain quadrillé et organisé.

25 Information Hélène Laubacher.

N.B. - Les photographies sont l'œuvre de Pierre Plattier (fig. $6, n^{\circ *} 3$ à $5 ;$ fig. $17, n^{\circ s} 3$ à 12) et de la ville de
L'ovalité du périmètre des remparts, qui a dû mettre à mal bien des parcelles, n'est pas un obstacle. A Lyon, le site du Verbe Incarné a montré que l'on n'hésitait pas à gagner sur l'habitat lorsqu'il s'agissait d'édifier quelque construction monumentale (Mandy, 1983). A Reims (Neiss, 1984), l'existence d'une ville organisée autour d'un cardo et d'un decumanus n'a pas empêché, au Bas-Empire, l'érection d'un rempart là aussi de forme ovale.

L'appréhension de nouvelles données susceptibles d'enrichir la connaissance de Grenoble dans l'Antiquité ne peut donc, semble-t-il, se priver d'une recherche archéologique conduite à partir des remparts. Grenoble possède, pour la Gaule, la seule enceinte du Bas-Empire bien datée: une fouille comprenant les remparts élargirait, dès lors que serait reconnu le sol de travail relatif à leur édification, le champ des investigations. Elle serait, pour le moins, riche d'enseignements sur trois points :

- la chronologie du faciès stratigraphique; il serait donc possible de vérifier les datations ou origines prêtées jusqu'ici à telle ou telle couche;

- la pérennité de l'habitat dans sa densité (occupation des niveaux successifs) et sa distribution spatiale (continuité d'un éventuel schéma directeur);

- la connaissance du matériel d'origine locale, celui récolté jusqu'à présent restant trop souvent peu exploitable pour avoir été recueilli dans des conditions toujours difficiles.

Ainsi scraient assurés, pour une meilleure connaissance des origines de Grenoble, les quelques éléments aujourd'hui encore trop imparfaitement certifiés après la seule étude de la fouille du parking Lafayette.

\section{Bernard DangréauX}

Grenoble : (fig. $3, \mathrm{n}^{\circ} 3$ ), atelier photo (fig. $18, \mathrm{n}^{\circ} 1$ ), CAHMGI (fig. 5).

Tous les dessins sont de l'auteur. $\mathrm{M}^{\mathrm{me}}$. Nora Esperguin a assuré la mise au net des figures 8 à 16 et $17, n^{\text {os }} 1$ et 2 . 


\section{ANNEXE}

\section{INVENTAIRE DU MATÉRIEL ENREGISTRE PAR FAIT ARCHÉOLOGIQUE}

Cet inventaire suit l'ordre adopté au chapitre II. Les numéros entre parenthèses qui figurent dans cette nomenclature renvoient à l'inventaire du musée Dauphinois de Grenoble. Le mobilier enregistré hors stratigraphie n'est pas mentionné ici.

\section{L'INTÉRIEUR DU BÂTIMENT}

PIËCE $1, B 20$

1 fond (75.28.661) en céramique peinte.

PIÉCE $1, B 10$

11 tessons de céramique commune sombre, non tournée,

1 tesson de céramique commune claire.

\section{PIÉCE 2, B8}

1 tesson de céramique commune claire,

1 lampe à volutes (75.28.696),

3 clous (dans lot 75.28.800).

PIÉCE 2, B7

1 bouton de couvercle en céramique commune sombre (75.28.299),

40 poids de suspension (75.28.706 à 745).

PIÉCE 2, B19

1 tesson de céramique commune sombre,

1 tesson de céramique commune claire.

PIÉCE $2, B 6$

1 tesson de céramique commune sombre,

3 tessons de céramique commune claire.

PIÉCE 2, B2

1 fond de céramique sigillée avec estampille JPR (75.28.202).

PIÉCE $2, B 3$

11 tessons de céramique sigillée (Gaule du Sud),

1 Drag. 27 (75.28.5),

2 Drag. $15 / 17$ (75.28.44 et 45$)$,

2 Drag. $18 / 31$ (75.28.57 et 58$)$,

1 Ritt. 9 ou Drag. 4/22 (75.28.204),

14 tessons de céramique commune sombre dont 2 fragments de fond,

1 fragment de panse ornée de côtes en relief (75.28.326), en céramique commune sombre,

7 tessons et 1 fragment de bol hémisphérique sablé (75.28.663), en céramique à parois fines,

1 fragment de fond de lampe à huile (75.28.702),

2 fragments de verre dont 1 bord de vase à lèvre arrondie (75.28.773),

9 clous (dans lot 75.28.800).

PIÉCE 2, B4

2 tessons de céramique sigillée ( 1 italique et 1 Gaule du Sud),

1 Drag. 27 (75.28.6),
1 fond de grand plat en céramique sigillée (75.28.206),

20 tessons de céramique commune claire,

1 assiette en céramique commune claire (75.28.464),

1 clou (avec lot 75.28.800).

PIÉCE 2, B16

1 tesson de céramique commune claire,

1 clou (avec lot 75.28.800).

PIÉCE 2, B5

1 tesson de céramique commune claire,

PIÉCE 2, BI

1 Ritt. 14 a (75.28.80),

1 Drag. 30 (75.28.143),

4 tessons de céramique commune sombre,

1 pot ovoïde à épaule carénée (75.28.219), en céramique commune sombre,

1 fragment de panse ornée de côtes en relief (75.28.327), en céramique commune sombre,

6 tessons de céramique commune claire,

1 assiette en céramique commune claire (75.28.464),

1 mortier à lèvre en bandeau (75.28.477),

1 bol de type Roanne en céramique peinte (75.28.657),

2 fragments de panse d'amphore,

1 fragment de verre incolore.

PIÉCE 2, B13

1 tesson de céramique commune sombre.

PIÉCE 2, B18

1 tesson de céramique commune claire.

PIÉCE 6 ET 7, B14

1 tesson de céramique sigillée (italique),

2 tessons de céramique commune sombre tournée,

9 tessons de céramique commune sombre non tournée,

1 bord d'assiette à paroi oblique et à lèvre rabattue vers l'intérieur (75.28.469) en céramique commune claire.

TOUTES PIĖCES, B11-B15

1 Goudineau 17 (75.28.1),

1 Drag. 15/17 (75.28.46),

1 fragment de verre de couleur verdâtre,

2 phiales côtelées, type Isings 3 a (75.28.754 et 755).

FAIT ISOLÉ, B9

1 mortier à lèvre pendante (75.28.478). 
FAIT ISOLÉ, BI2

1 calice en verre (75.28.754) type Isings 36 a/MorinJean 98.

FAIT ISOLÉ, B17

1 couvercle en céramique commune sombre (75.28.286)

\section{L'EXTÉRIEUR DU BÂTIMENT}

ANGLE 2, E1

1 Drag. $15 / 17$ (75.28.50),

1 Drag. 18/31 (75.28.59),

2 Drag. 35 (75.28.82 et 83 ),

1 tesson de céramique sigillée (Gaule du Sud),

3 tessons de céramique commune sombre.

ANGLE 2, E2

8 tessons de céramique commune claire.

ANGLE 2, E3

6 tessons de céramique commune claire.

ANGLE 3, E5

2 fragments de céramique sigillée ( 1 de la Gaule du Sud, 1 de provenance indéterminée).

FACADE NORD-OUEST, E4 (couche 7)

1 fragment de faucille (75.28.792).

FACADE NORD-ouest, D4 (couche 7)

1 tesson de céramique à vernis noir,

1 tesson de céramique commune sombre,

4 tessons de céramique commune claire,

2 assiettes ou coupelles (75.28.468 et 470 ) en céramique commune claire,

1 bol de type Roanne (75.28.659) en céramique peinte,

1 fragment d'anse d'amphore Dr. 20 (75.28.691),

1 fragment de col d'amphore (75.28.676).

\section{Faits isolés}

\section{$F_{A I T} D 1$}

sigillée

35 tessons (ateliers de la Gaule du Sud),

2 Drag. 27 pour 3 fragments (75.28.8 à 10),

2 Drag. 24/25 (75.28.24 et 25),

2 Ritt. 9 (75.28.31 et 32$)$,

4 Drag. 33 (75.28.36 à 39$)$,

3 Drag. $15 / 17(75.28 .47,48$ et 49$)$,

2 Drag. 18/31 (75.28.60 et 61$)$,

3 Drag. $4 / 22$ (75.28.67 à 69),

2 Ritt. 12 (75.28.77 et 78 ,

1 Ritt, 14 b (75.28.81),

9 Drag. 35, dont trois décorés à la barbotine, pour 13 fragments $(75.28 .84$ à $94,97,98)$,

1 Drag. 36 décoré à la barbotine (75.28.95),

1 Drag. 36 lisse (75.28.96),

1 Curle 11 (75.28.116),

1 Hermet 7 (75.28.119),

4 Drag. 29 pour 7 fragments (75.28.124 à 130),

1 Drag. 30 (75.28.144),

11 Drag. 37 pour 19 fragments (75.28.148 à 166),
1 forme indéterminée pour 2 fragments (75.28.198 et 199),

1 fond de grand plat (75.28.207),

tous provenant des ateliers de la Gaule du Sud sauf 1 Drag. 37 (Centre de la Gaule), 1 Drag. 35 lisse et la forme indéterminée (non localisés).

commune sombre

15 tessons de céramique non tournée,

120 tessons de céramique tournée, dont 9 bords et 19 fonds

7 pots ovoïdes à épaule carénée $(75.28 .214,217,218$, $220,228,231$ et 232),

3 pots ovoïdes à épaule côtelée (75.28.233 à 235),

1 pot ovoïde (75.28.239),

1 bol caréné (75.28.241),

2 coupes à lèvre débordante (75.28.247 et 248),

8 assiettes, 1 à paroi rectiligne (75.28.255), 4 à paroi concave (75.28.262 à 264 et 266), 2 à lèvre triangulaire (75.28.257 et 259), 1 à fond tripode (75.28.273),

3 couvercles $(75.28 .280,281$ et 282$)$ et 7 fragments de bord de couvercle.

commune claire

266 tessons dont 2 bords, 10 anses et 13 fonds,

1 pot ovoïde (75.28.442),

4 cruches $(75.28 .449,456,459,460)$,

1 assiette ou coupelle à bord rentrant (75.28.466),

13 mortiers, dont 1 à lèvre en bandeau (75.28.476) et 12 à lèvre pendante (75.28.484 à 495), et 7 fonds,

1 coupe avec collerette sous la lèvre (75.28.655).

céramique peinte

1 bol de type Roanne (75.28.658).

parois fines

1 pied de bol (75.28.665).

dolia et amphores

3 dolia $(75.28 .669,670,672)$,

1 fragment de col d'amphore (75.28.686),

1 anse d'amphore Dr. 20, estampillée P.I.R. PO (75.28.690),

2 amphorisques (75.28.693 et 694) et 17 fragments de panse d'amphore.

lampes à huile

3 fragments (75.28.697, 699 et 703 ) dont un fond signé [FORTI] $S$.

verre

6 phiales côtelées $(75.28 .758$ à 763$)$ dont 3 de type Isings $3 \mathrm{~b}$,

1 bord de vase à col étranglé (75.28.769),

1 fragment de panse décorée (75.28.770),

1 fond de balsamaire (75.28.776) de type Isings $82 \mathrm{bl}$,

1 fond de flacon (75.28.777),

2 fragments de fond de bouteille à panse prismatique (75.28.778 et 779 ) et 2 fragments de verre incolore.

divers

2 poids de suspension (75.28.746 et 747 ),

1 objet indéterminé en métal (75.28.798). 
N.B. - Les fragments d'un pot ovoïde à épaule carénée (75.28.214) et ceux d'un couvercle (75.28.281) recollent avec des tessons extraits du puits.

\section{FAIT D2}

17 tessons de céramique sigillée de la Gaule du Sud,

1 Drag. 27 (75.28.11),

1 Drag. $15(75.28 .26)$,

1 Ritt. 9 (75.28.30),

1 Drag. 33 (75.28.40),

1 Drag. 35, décoré à la barbotine (75.28.99),

2 Drag. 36 (75.28.100 et 101$)$,

1 Curle 15 (75.28.118),

1 Drag. $30(75.28 .143)$,

3 Drag. 37 pour 10 fragments (75.28.167 à 176),

1 fond en céramique sigillée (75.28.194),

1 fond de plat (75.28.208) en céramique sigillée, tous provenant des ateliers de la Gaule du Sud.

\section{FAIT D3}

63 tessons de céramique commune sombre,

1 assiette à paroi rectiligne (75.28.256) en céramique commune sombre,

1 tesson de céramique commune claire,

2 tessons de céramique à parois fines,

1 clou (avec lot 75.28.800).

\section{Puits}

sigillée

9 tessons (ateliers de la Gaule du Sud),

1 Drag. 15 (75.28.28),

1 Drag. 33 (75.28.43),

1 Drag. 4/22 (75.28.70),

3 Drag. 35 lisses (75.28.102 à 104),

1 Drag. 36 lisse (75.28.105),

1 Curle 11 (75.28.117),

1 Hermet 7 (75.28.120),

1 Drag. 38 (75.28.123),

2 Drag. 29 (75.28.132 et 133$)$,

1 Drag. 30 (75.28.145),

1 Drag. 37 (75.28.177),

1 forme indéterminée,

tous provenant des ateliers de la Gaule du Sud à l'exception des Drag. 36 et 38 (Centre de la Gaule), d'un Drag. 35 et de la forme indéterminée (non localisés).

commune sombre

18 tessons de céramique commune sombre non tournée,

316 tessons de céramique commune sombre tournée, dont 11 bords et 20 fonds,

3 pots ovoïdes à épaule carénée $(75.28 .214,215$ et 225),

2 pots ovoïdes à épaule côtelée (75.28.236 et 237),

1 pot ovoïde (75.28.238),

1 bol à col déversé (75.28.242),

5 assiettes, 1 à bord déversé (75.28.260), 3 à paroi concave (75.28.261, 265 et 268), 1 à bord rentrant (75.28.271),
2 cruches (75.28.275 et 276) dont une à bec tréflé,

1 pichet à lèvre en bandeau (75.28.277),

2 pichets à col tronconique (75.28.278 et 279),

2 couvercles $(75.28 .281$ et 298) et 6 fragments de bord de couvercle,

4 fragments de vases décorés de guillochis (75.28.323 et 324 ), de croisillons incisćs (75.28.325) ou au lissage (75.28.328).

\section{allobroge}

3 vases ou fonds de vase (75.28.431 à 433).

\section{commune claire}

804 tessons, dont 22 bords et 49 fonds,

5 pots ovoïdes $(75.28 .435,436,439,440,441)$,

6 pichets (75.28.443 à 448),

7 cruches $(75.28 .450$ à $452,454,455,462,463)$,

1 assiette ou coupelle à bord rentrant (75.28.465),

1 mortier à lèvre en bandeau (75.28.475),

6 mortiers à lèvre pendante (75.28.479 à 484 et 514),

1 mortier à grande lèvre formant collerette (75.28.517),

3 coupes à lèvre tombante (75.28.652 à 654),

1 coupe avec collerette en milieu de panse (75.28.656).

dolia, amphores et amphorettes

5 dolia $(75.28 .666$ à $668,671,673)$,

1 amphore Beltrán IIa (75.28.675),

9 amphorettes (75.28.677 à 685).

lampe à huile

1 fragment de couvercle $(75.28 .705)$.

verre

2 fragments de phiale côtelée (75.28.764 et 765) type Isings 3 ,

1 bord de vase à lèvre horizontale (75.28.772),

1 fragment de fond de bouteille à panse prismatique (75.28.780).

bois

1 bol en buis (75.28.785),

1 peigne (75.28.786),

1 axe de bobine de fil? (75.28.787),

1 grain d'enfilage (75.28.788),

1 baratte (?) à cinq branches rayonnantes (75.28.789),

1 tonnelet (75.28.790).

métal

1 serpette d'élagueur (75.28.791),

1 fragment de faucille? (75.28.793),

2 anneaux (75.28.795 et 796 ),

1 objet indéterminé (75.28.799),

14 clous (avec lot 75.28.800).

divers

4 poids de suspension (75.28.748 à 751$)$.

N.B. - On ajoutera aux fragments d'un pot ovoïde à épaule carénée et d'un couvercle qui recollent avec des tessons recueillis en $\mathrm{Dl}$, un mortier à lèvre pendante (75.28.479) complété avec des tessons répertoriés en H.S. 


\section{BIBLIOGRAPHIE}

Barbet A.

1982-1983: La diffusion du III' style pompéien en Gaule, Gallia, 40, p. 53-82 (première partie) et 41, p. 111-165 (seconde partie).

1984: Pour un langage commun de la peinture murale romaine, essai de terminologie; Centre d'ètudes des peintures murales romaines, Bulletin de liaison $n^{\circ} 7$, École Normale Supérieure, Paris.

Benoit F.

1947 : Histoire de l'outillage rural et artisanal, Paris.

Blanchard R.

1935 : Grenoble, ètude de géographie urbaine, Paris, Armand Colin.

Bocquet A.

1963: Rapport de fouilles effectuées rue de la République à Grenoble, (inédit).

1968 : De Cularo à Gratianopolis; quatre siècles d'histoire, Le vieux Grenoble, ses pierres et son âme, Grenoble, II, p. 255-258.

Bocquet A. et Colardelle $\mathbf{M}$.

1974 : Rapport de fouilles d'urgence : Grenoble "parking Lafayette», (inédit).

Callender M. H.

1965 : Roman amphorae with index of slamps, Londres.

Chapotat G.

1970 : Vienne gauloise, le matériel de La Tène III trouvé sur la colline de Sainte-Blandine, Lyon.

Collectif

1984 : Fouilles du quartier des filles-IDieu au Mans, Archéologie des lacs et rivières, Annecy, p. 56-57.

Colls D., Étienne R., Lequément R., Liou B., Mayet F.

1977: L'épave de Port-Vendres II et le commerce de la Bétique à l'époque de Claude, Archaeonaulica, 1.

Dangréaux B.

1986: Les origines de Grenoble: l'état des connaissances, Cahiers d'Histoire, XXXI, I, p. 3-22.

Dangréaux B., Jospin J.-P.

1986: La céramique allobroge du Musée Dauphinois de Grenoble, Actes du congrès de la Socièté française d'Étude de la Céramique antique en Gaule, Toulouse 1986, Marseille, p. 145154.

Darton A.

1972 : Sigillée claire B de la vallée du Rhône, Revue d'Éludes ligures, XXXVIII, 2, p. 137-189.
Desbat A.

1981: L'architecture de terre à Lyon à l'époque romaine, Récentes recherches en archéologie gallo-romaine el paléochrétienne sur Lyon et sa région, B.A.R. International Series, 108, p. 5581.

1983 : La région de Lyon et de Vienne in : Architectures de terre et de bois, Actes du 2 Congrès archéologique de Gaule méridionale, Lyon, novembre 1983 (J. Lasfargues dir.), DAF, 2, p. 75-83.

Desbat A., Laroche C., Mérigoux E.

1979 : Note préliminaire sur la céramique commune de la rue des Farges à Lyon, Figlina, 4, p. 1-17.

Desbat A., Baudrand M.-N., Kroichvili A., Leblanc O., Plattier P., Tavernier D., Savay-Guerraz H.

1983 : Saint-Romain-en-Gal, rapport de fouille 1983, (inédit).

Goudineau Chr.

1968 : La céramique arétine lisse, Paris, de Boccard.

Isings $\mathrm{C}$.

1957 : Roman Glass from Dated Finds, Archaeologica Trajectina$I I$, Groningen, Djakarta.

Laroche C

1988: Aoste (Isère) un centre de production céramique fin $\mathrm{I}^{\mathrm{er}}$ av. J.-C./fin $\mathrm{I}^{\mathrm{er}}$ ap. J.-C., fouilles récentes 1983-1984, Revue archéologique de Narbonnaise (à paraitre).

Le Gall J.

1975 : Les Romains et l'orientation solaire, MEFRA, p. 287319 .

Mallon J., Marichal R., Perrat Ch.

1939 : L'écriture latine de la capitale romaine à la minuscule, Paris.

Mandy B.

1983 : Le quartier antique du Verbe Incarné, Dossiers IIistoire el Archéologie, 78, p. 23-26.

Morin-Jean

1913 : La verrerie en Gaule sous l'Empire romain, Paris.

Müller $\mathrm{H}$.

1930 : Les origines de Grenoble, Paris, Arthaud.

Neiss R.

1984 : La structure urbaine de Reims antique et son évolution du I $^{\text {er }}$ au III siècle ap. J.-C., Revue archéologique de Picardie, $3-4$, p. 171-191. 
Odenhart-Donvez I.

1983: Les verres du chantier de la rue des Farges à Lyon, mémoire de Maîtrise, université Jean Moulin, Lyon III, (inédit).

Oswald F.

1964 : Index of polter's stamps on terra sigillata, Londres.

Oswald F., Pryce D.

1966 : An Introduction to the study of Terra Sigillata, Londres.

Paunier D.

1981 : La céramique gallo-romaine de Genève, Droz.

\section{Périchon R.}

1974 : Les poteries gauloises, Les dossiers de l'archéologie, 6, p. 9-19.

\section{Picon M.}

1973 : Introduction à l'étude technique des céramiques sigillées de Lezoux, Centre de Recherches sur les Techniques grécoromaines, 2 , université de Dijon.

\section{Ponsich M.}

s.d. : Les lampes romaines en terre cuite, Notice technique $d u$ Touring Club de France, 9, Paris.

\section{Sénéchal R.}

1975 : Céramiques commune d'Alésia: les cruches, Centre de Recherches sur les Techniques gréco-romaines, 5 , université de Dijon.

Vernhet A.

1975 : Noles sur la terre sigillée de La Graufesenque, Millau. 1976 : Création flavienne de six services de vaisselle à La Graufesenque, Figlina, 1, p. 13-27.

1977 : Les dernières productions de La Graufesenque et la question des sigillées claires B, Figlina, 2, p. 33-49.

\section{Viérin J., Leva Ch.}

1961 : Un puits à tonneau avec sigles et graffiti à Harelbecke; Latomus, XX, p. 759-805. 